\title{
Inspectors or Google Earth? Optimal fiscal policies under uncertain detection of evaders*
}

\author{
Martin Besfamille $^{\dagger} \quad$ Pablo Olmos ${ }^{\ddagger}$
}

August 11, 2010

\begin{abstract}
Most of the contributions to the optimal tax-enforcement literature assume that audits are perfect and always discover evaders. However, evasion often remains undetected. To reduce the probability of such a failure, governments invest resources to improve their tax administrations' detection technology.

We incorporate these kind of investments into a model that studies optimal fiscal policies under uncertain detection of evaders. We characterize their level and we show numerically how they interact with the other dimensions of an optimal fiscal policy. Finally, we highlight the differences between our results and those obtained in a model without investment in audit technology.
\end{abstract}

Keywords: Tax evasion - Tax rates - Enforcement - Imperfect audits - Investments in tax administration

JEL Codes: D82 - H26 - H83

\section{Introduction}

Tax evasion threatens the equity and the efficiency concerns of fiscal policies. Therefore, governments adopt actions to ensure compliance with the tax law: audits are conducted to verify whether tax liabilities have been met and evaders are penalized. However, this 'enforcement approach' is not sufficient. As the extent of this misbehavior also depends upon the tax structure, the fight against tax evasion cannot be isolated from its design.

*We thank S. Urbiztondo for suggesting to us the issue analyzed in this paper, and L. Arozamena, D. Bardey, D. McPartland, R. Torregrosa and E. Zilberman for very useful comments. J. Dubra and R. Arias made helpful suggestions on a previous version of the paper. We also thank participants at 2010 IRS Research Conference (Washington DC), $42^{\circ}$ Jornadas Internacionales de Finanzas Públicas (Córdoba), PET 2010 (Istanbul) and seminar participants at Universidad de Montevideo.

†Corresponding author. Department of Economics, Universidad Torcuato Di Tella. E-mail: mbesfamille@utdt.edu

${ }^{\ddagger}$ Department of Economics, Yale University. 
Since Sandmo (1981), many articles have analyzed, in different settings, optimal taxenforcement policies, or 'optimal tax systems' (in Slemrod's (1990) terminology). ${ }^{1}$ Almost all contributions to this literature assume that audits are perfect: they always reveal the auditee's private information. But this assumption is far from being realistic, as already recognized by Alm (1988), Reinganum and Wilde (1988), Beck and Jung (1989), Scotchmer and Slemrod (1989), Cowell (1990), and then empirically confirmed by Feinstein (1991) and Erard and Feinstein (2010). ${ }^{2}$ This failure to detect evaders clearly modifies the analysis of optimal tax-enforcement policies, as suggested by Cowell (1990) and formally shown by Boadway and Sato (2000).

Once this is acknowledged, one can go one step further and address the following issue. Is the detection rate only an exogenous parameter that affects the design of an optimal fiscal policy, as in Boadway and Sato (2000)? Or do governments invest resources to improve their tax administrations' detection technology, making it an endogenous element of their fiscal policy? From a theoretical point of view, this last possibility cannot be ignored, and deserves scrutiny. More importantly, the existence of governments that make these kind of investments is an empirically relevant fact, as the following paragraphs illustrate.

In 1998, the US Congress created a special 'Information Technology Investment' account, to fund IRS's modernization activities. With these funds, in 1999, the IRS launched 'Business Systems Modernization' (BSM), an ambitious multianual project to modernize its information technology infrastructure. One of the its pillars is the change of the old data system, the Master File system. Among others, the Master File system has an important drawback. The entire process the IRS needs to enter account data into the Master File and make the updated information available for researching taxpayer accounts can take from four to six weeks. Because of these delays, IRS employees frequently have inconsistent and out-of-date information about a given taxpayer. Under these circumstances, conducting timely audits and going after tax evaders is extremely difficult. The Master File system will be replaced by the Customer Account Data Engine (CADE), which will allow IRS's employees to post changes and update taxpayers accounts and returns from their desks. According to the IT 'Modernization Vision \& Strategy' guidelines (IRS, 2007a), CADE will improve quality of examinations by reducing errors and timely detection of non-compliers.

When these kind of investments are successful, ${ }^{3}$ their returns seem to be more spectacular in less developed countries, like in Argentina. In February 2007, the Dirección de Rentas de la Provincia de Buenos Aires (the tax authority of the Buenos Aires province) subscribed to Google Earth to download high-quality satellite images that could serve as evidence of evasion to the property tax. This technology enabled the tax agents to discover, in less than one semester, 68,844 undeclared properties, 1,458 undeclared swimming-pools

\footnotetext{
${ }^{1}$ See among others Usher (1986), Slemrod and Yitzhaki (1987), Border and Sobel (1987), Mookherjee and Png (1989), Cremer, Marchand and Pestieau (1990), Kaplow (1990), Mayshar (1991), Sanchez and Sobel (1993), Pestieau, Possen and Slutsky (1994, 2004), Slemrod (1994), Cremer and Gahvari (1994, 1995), Marhuenda and Ortuño-Ortín (1997), Chander and Wilde (1998), Boadway and Sato (2000) and Besfamille and Parlatore Siritto (2009).

${ }^{2}$ Using data from the Internal Revenue Service (IRS), these authors estimate that detection rates vary between 30 and $50 \%$.

${ }^{3}$ Radian (1980) describes how the tax administration of Trinidad and Tobago, Jamaica, Thailand and Philippines could not manage to use properly newly (and successfully) installed computer systems.
} 
and more than 13 million square meters with undeclared silos (La Nación, August $27^{\text {th }}$ 2007).

Investments made by governments to improve their tax administration's detection capacity have been described by Snavely (1988), and more recently by Bird and Zolt (2008). In empirical studies, they have also been included as a explanatory variable for the estimation of the IRS's productivity (Hunter and Nelson 1996) and the aggregate income tax evasion in the United States (Cebula 2001). But, as recognized by Bird and Zolt (2008), they have not been incorporated into the formal analysis of optimal tax-enforcement policies so far. We address this issue in a simple three-stage model, with two classes of active agents: individuals and a government. Each individual can be poor or rich; rich individuals earn the highest taxable income. Rich individuals are also characterized by their fiscal ethics: they can be honest or dishonest. Honest always comply with the tax law; whereas dishonest may not, if this is beneficial to them. In order to maximize an utilitarian social welfare criterion, the government sets a fiscal policy, as follows. In the first stage of the model, the government invests resources to improve the tax administration's detection capacity. In the second stage, the government designs and announces the tax law. This law includes the tax schedule and the enforcement policy to be conducted later on by the tax administration. Finally, in the last stage of the model, the tax administration collects taxes and enforces the tax law. As incomes are private information, individuals are requested to report them. Then, the tax administration audits reports according to the frequency pre-specified by the government. Audits are costly and discover only randomly whether a taxpayer has misreported. The probability of catching an evader (called the detection probability) is an increasing function of the initial investment and its productivity. When a misreport is found out, the tax administration taxes the evader according to his true income and imposes him an additional fine. With all revenues collected (taxes and fines, net of investment and audit costs), the government finances the provision of a public good.

As a benchmark, we derive the optimal fiscal policy under full information, when enforcement is not necessary. Then, we assume asymmetric information and we solve the model backwards. In the second stage, two audit regimes emerge, depending upon the value of the detection probability. In the first regime, when the detection probability is relatively high, the government designs a tax law that will be enforced. The incentivecompatible enforcement policy is such that the tax administration only audits individuals that have reported to be poor. In order to attenuate the rich taxpayers' stake for evasion, taxes are optimally distorted with respect to their full-information level: rich (poor) individuals pay less (more) than in the benchmark. We also show that improvements in the detection technology imply more progressive optimal tax schedules. Regarding the optimal audit probability, it can monotonically increase with the detection probability or have an inverse U-shaped curve. Moreover, under some parameter configurations of the model, the government may impose the tax administration to audit all individuals having reported to be poor. In the second regime, when the detection probability is relatively low, the government designs a tax law that will not be enforced, implying that evasion emerges at the optimum. When all rich taxpayers are dishonest, taxation has to be uniform among all individuals. But if some rich individuals are honest, the government can tax them more than the others. Again, we characterize the optimal tax schedule: the poor pay more than 
under full information, whereas the rich are taxed at the same level.

Next we move to the first stage. The investment decision has an impact not only on the expected social welfare (because tax revenues are allocated to investment instead of being allocated to the public good) but can also fix under which regime the government and the tax administration will be afterwards. Although we prove that an optimal investment exists, we cannot completely characterize it in general, due to the non-convexity of the government's problem at this stage.

Thus, to identify the optimal investment's level, to quantify the other components of the optimal fiscal policy and to obtain comparative statics results, we simulate numerically the model for parameter values representative of the US tax system and the IRS's operations in 2006. The simulations show that incorporating investments that improve the tax administration's capacity to detect evaders in a model of optimal tax-enforcement policies under imperfect auditing modifies its results substantially. First, the simulations clarify the relation between investment and expenditures in audit. Although investment improves the detection probability, which one could think that it may imply a reduction in audit operations, the aggregate audit cost can increase. Moreover, investment and audits can be substitutes or complements. Second, the different ways of making the income distribution less equal from the top (i.e. changing the fraction of rich in the population or their taxable income) do not have the same impact upon the optimal level of investment. Also, the more equal the income distribution is, the less progressive/more regressive the tax structure becomes. Finally, all simulations show that the public sector becomes more efficient (i.e., the fraction of tax collection used to provide public goods increases) with investments. Clearly, these results suggest that, in future empirical research on tax policies, investments like those analyzed in this paper should be incorporated to the currently used definitions of 'tax effort'.

The remainder of this paper is organized as follows. Next section describes the model, discusses the assumptions and presents the optimal fiscal policy under full information. Section 3 analyzes the optimal fiscal policy under asymmetric information. Section 4 simulates numerically the model and presents the results. Section 5 discusses related literature and Section 6 concludes. All proofs appear in the Appendix.

\section{The model}

There is a continuum of taxpayers of measure one. Each taxpayer $i$ has an individual income $y_{i}$, which is a random variable that takes values in the set $\left\{y_{p}, y_{r}\right\}$, with $0<y_{p}<y_{r}$. A taxpayer with income $y_{r}$ is henceforth called 'rich'; otherwise, he is called 'poor'. Each taxpayer's income $y_{i}$ is his private information. All individual incomes are i.i.d., and the probability that $y_{i}=y_{r}$ for any given individual $i$ is $\mu \in(0,1)$, which is common knowledge. ${ }^{4}$

In addition, each taxpayer may be 'honest' or 'dishonest,' and this is his private information as well. Dishonest taxpayers file their tax returns by choosing to report the income

\footnotetext{
${ }^{4}$ Measurability issues may arise in probability spaces with a continuum of i.i.d. random variables, as it is the case in our setting. In spite of this, we will adopt throughout the paper the usual abuse of the Law of Large Numbers. Hence $\mu$ also represents the proportion of rich individuals in the population.
} 
level that maximizes their expected utilities. In other words, these taxpayers are potential evaders. On the contrary, honest taxpayers always file truthful reports. Any given rich taxpayer is dishonest with probability $\theta \in[0,1],{ }^{5}$ and this is common knowledge -it will be clear later on that whether a poor taxpayer is honest or dishonest is irrelevant, so we ignore this issue.

Taxpayer $i$ 's ex-post welfare is given by

$$
W_{i}=u\left(q_{i}\right)+g
$$

where $q_{i}$ is his private-good consumption, and $g$ is the government's provision of a public good. The private good is the numeraire. The strictly increasing and concave utility function $u\left(\right.$ ) satisfies $^{6}$

$$
u(0)=0, u_{q}>0, \lim _{q \rightarrow 0} u_{q}=\infty \text { and } \lim _{q \rightarrow \infty} u_{q}=0 .
$$

To obtain interior solutions, we further assume that $u_{q}\left(y_{p}\right) \ll 1$.

The government designs a fiscal policy to maximize the utilitarian criterion

$$
W=\mu W_{r}+(1-\mu) W_{p} .
$$

The order of events, and relevant features of the model in more detail, are as follows.

1. In the first stage, the government invests capital $\kappa$ to improve the tax administration's capacity to detect evaders. The capital's price is normalized to one.

2. In the second stage, the government designs and announces the tax law, which specifies the tax schedule $\left(t_{p}, t_{r}\right)$ and the enforcement policy to be conducted by the tax administration afterwards. The enforcement policy consists specifically of audit probabilities and fines for evaders. Due to institutional constraints, the tax law has to verify taxpayers' limited liability, horizontal and vertical equity.

3. In the third stage, the tax law is implemented. As the tax administration does not observe incomes, taxpayers are requested to report them, e.g. by filling in an income tax form. We denote such reports by $\widetilde{y}_{i}$. Then, following the enforcement policy previously designed by the government, the tax administration audits each report with probability $\pi_{\widetilde{y}} \in[0,1]$. Each audit $\operatorname{costs} c>0$.

If a taxpayer is not audited, he pays the tax that corresponds to his report. ${ }^{7}$ If he is audited, the tax administration discovers a misreport with probability $\delta$ : audits are imperfect. The detection probability $\delta$ is a continuous and strictly increasing function $\delta(\kappa, \nu)$, where $\nu>0$. The function $\delta()$ satisfies

$$
\lim _{\kappa \rightarrow 0} \delta=\delta_{\iota} \text { and } \lim _{\kappa \rightarrow \infty} \delta \leq 1 .
$$

\footnotetext{
${ }^{5}$ The particular case were all rich taxpayers are potential evaders $(\theta=1)$ is precisely the framework adopted by most of the contributions to the optimal tax-enforcement literature. Therefore, by letting the parameter $\theta$ to take any value within $[0,1]$, we generalize some of the results of this literature.

${ }^{6}$ Throughout the paper, subscripts of functions denote partial derivatives.

${ }^{7}$ For the sake of simplicity, we assume that tax collection is costless, both for taxpayers and for the tax administration.
} 
On the one hand, the initial level $\delta_{\iota}$ is exogenously determined by technology and human capital available to the tax administration at the beginning of the first stage, and by other parameters related to the difficulty of observing true incomes. On the other hand, the exogenous parameter $\nu$ affects the function $\delta()$ as follows: the higher the $\nu$, the higher the capacity of any level of investment to improve the detection probability $\delta$. This is the reason to call $\nu$ the 'investment productivity'. As mentioned by Bird and Zolt (2008), its value depends, among other things, on the training, skills and resistance to change of the people who are expected to operate the (new) technology.

If a misreport is detected, the evader has to pay the tax that he legally owes, plus the additional fine $f .{ }^{8}$ Finally, with all revenues collected (taxes and fines, net of investment and audit costs), the government finances the provision of the public good $g$, whose unit cost is also normalized to one.

The assumptions of the model deserve some comments. To simplify the model,${ }^{9}$ we assume that the government makes all decisions. The tax administration is simply a 'machine' that follows the government's directives, unlike in Cremer, Marchand and Pestieau (1990) and Sanchez and Sobel (1993), where the tax administration decides the audit strategy. In spite of this, and for the sake of realism, we follow these authors in separating (only formally) the tax administration from the government.

Concerning the investment decision, two observations can be made. First, and related to the previous comment, the fact that the government chooses the investment's level replicates the US Congress creating an special account for the IRS, with funds to be used only for the modernization of its information technology. Second, the lag between the investment decision and the design of the tax law is clearly a shortcut, reflecting the longterm character of these kind of investments (made once, but with an impact that carries over many years) with respect to the sort-term of the (designed yearly) tax law.

Regarding full commitment to the enforcement policy, this assumption generates a framework where, a priori, investments should have the lowest value (because they are not worth as commitment devices). We could have adopted two other assumptions: partial commitment (see Melumad and Mookherjee 1989) or no commitment (see Graetz, Reinganum and Wilde 1986). These other assumptions, although more realistic, do not modify the main results regarding the optimality of investing in the tax administration.

Adding more income levels would enhance the possibilities of redistribution and alter the shape of the enforcement strategy. ${ }^{10}$ But, as the main contribution of our paper is to analyze the impact of investments in detection technology upon the progressivity of the tax structure and the provision of public goods, such generalization would not affect qualitatively the results.

\footnotetext{
${ }^{8}$ Horizontal equity prevents rewarding truthful reports. Therefore, like Mookherjee and Png (1990) and Marhuenda and Ortuño-Ortín (1997), we rule them out of the model.

${ }^{9}$ Vakneen and Yitzhaki (1989) comment on the necessity of simplifying the models that deal with problems analyzed here.

${ }^{10}$ With more than two income levels, optimal audit probabilities may not be monotonic in income, as shown by Mookherjee and Png (1989, 1990).
} 
The existence of honest taxpayers has been recognized for a while in the economics literature on tax compliance (see Torgler 2007). Among the first to acknowledge this, Spicer and Lundstedt (1976) point out that attitudes and norms do affect evasion decisions. Baldry (1986) reports that some people never evade, no matter the level of tax rates, audit probabilities or sanctions. According to Gordon (1989), Benjamini and Maital (1985) were the first to incorporate moral costs into a formal model of individual evasion decisions.

As noted by Andreoni, Erard and Feinstein (1998), "an unresolved question is whether cheaters should be given the same weight in the social criterion function as honest taxpayers." We follow the literature on tax evasion, which provides a positive answer to this question.

We could have assumed an exogenous revenue requirement. Instead, we postulate that the government raises money to provide a public good. This enables us to obtain its optimal level, and thus to study in detail the trade-off between providing more public good or investing in a detection-improving technology. Finally, the reason for assuming individual utilities to be quasi-linear in the public good is purely technical. This assumption, which is not unusual, ${ }^{11}$ is sufficient to guarantee non-ambiguous signs in the comparative statics analysis at the second stage.

The goal of the paper is to characterize the optimal fiscal policy under asymmetric information about individual incomes. Before doing that, and in order to have a benchmark, we present the optimal fiscal policy under full information. In this case, the tax administration observes incomes and thus audits are useless. Anticipating this, the government does not need to invest at the initial stage and simply solves the following problem, where private consumption has been replaced, using taxpayers' budget constraints, by their disposable income

$$
\mathcal{P}^{*} \begin{cases}\underset{t_{p}, t_{r}}{\operatorname{Max}} \mu u\left(y_{r}-t_{r}\right)+(1-\mu) u\left(y_{p}-t_{p}\right)+g & \\ \text { subject to } & \left(L L_{p}\right) \\ t_{p} \leq y_{p} & \left(L L_{r}\right) \\ t_{r} \leq y_{r} & (B) \\ g=\mu t_{r}+(1-\mu) t_{p} & \end{cases}
$$

We denote by $\left(L L_{p}\right),\left(L L_{r}\right)$ the limited liability constraints, and by $(B)$, the government's budget constraint. The following expression

$$
u_{q}\left(y_{p}-t_{p}^{*}\right)=u_{q}\left(y_{r}-t_{r}^{*}\right)=1
$$

characterizes the optimal full-information tax schedule $\left(t_{p}^{*}, t_{r}^{*}\right)$. Given our assumptions, we have $0<t_{p}^{*}<y_{p}$ and $t_{p}^{*}<t_{r}^{*}<y_{r}$ : both limited liability and vertical equity hold strictly. As the social welfare criterion is separable between private and public consumption, and because the public good's provision equals the tax collection, the government taxes rich

\footnotetext{
${ }^{11}$ Utilities that are linear in the public good have been recently adopted in the public economics literature. For example, Ray and Vohra (2001) and Bloch and Zenginobuz (2006) use them in models of public goods provision.
} 
and poor individuals to equalize their marginal utility of consumption with their marginal utility of the public good. We denote by $g^{*}$ the optimal full-information level of public good.

\section{Optimal fiscal policy under asymmetric information}

In this section, we characterize the optimal fiscal policy under asymmetric information, ${ }^{12}$ when the tax administration tries to detect evaders by auditing income reports. As usual, we solve the model backwards. As the last stage is purely mechanical and involves no optimization, we start with the penultimate one.

\subsection{The optimal tax law}

As happens in Pestieau, Possen and Slutsky (1994, 2004) and Besfamille and Parlatore Siritto (2009), there are two possible enforcement regimes in this model. But here, we relate their emergence to the value of the detection probability $\delta$, not to the level of the audit cost, as it was the case in those articles.

\subsubsection{The audit regime}

When the detection probability $\delta$ is relatively high, the government enforces the tax law. Under this regime, the revelation principle applies (see Mookherjee and Png 1990); the optimal tax law can be characterized adopting a mechanism-design approach. As vertical equity imposes $t_{p} \leq t_{r}$, poor taxpayers will never misreport. ${ }^{13}$ The unique incentive problem the tax administration faces is rich taxpayers' intent to evade their due tax, by underreporting their income. Thus, the tax administration does not need to audit a taxpayer that has reported to be rich; it has to restrict its enforcement effort only to examine low income reports. Thereinafter, $\pi_{p}$ will denote the probability of auditing an announcement $\widetilde{y}_{p}$, and $f_{r, p}$, the fine to impose to an evader, i.e. to a rich that has reported to be poor. The optimal tax law $\left(t_{p}, t_{r}, f_{r, p}, \pi_{p}\right)$ solves the following problem, where again private consumptions have been replaced by taxpayers' disposable income, but now at each possible final state of the

\footnotetext{
${ }^{12}$ When $\theta=0$ (i.e. when all rich taxpayers are honest), asymetric information is not an issue, and thus the outcome is identical to the full-information benchmark.

${ }^{13}$ That is why distinguishing between honest and dishonest poor taxpayers is irrelevant.
} 
game.

$$
\mathcal{P}_{2} \begin{cases}\underset{t_{p}, t_{r}, f_{r, p}, \pi_{p}, g}{\operatorname{Max}} \mu u\left(y_{r}-t_{r}\right)+(1-\mu) u\left(y_{p}-t_{p}\right)+g & \\ \text { subject to } & \\ 0 \leq \pi_{p} \leq 1 & \left(L L_{p}\right) \\ t_{p} \leq y_{p} & \left(L L_{r}^{\prime}\right) \\ t_{r}+f_{r, p} \leq y_{r} & \\ u\left(y_{r}-t_{r}\right) \geq\left(1-\delta \pi_{p}\right) u\left(y_{r}-t_{p}\right)+\delta \pi_{p} u\left(y_{r}-t_{r}-f_{r, p}\right) & (I C) \\ g=\mu t_{r}+(1-\mu) t_{p}-(1-\mu) \pi_{p} c-\kappa & \left(B^{\prime}\right)\end{cases}
$$

Now we denote by $\left(L L_{r}^{\prime}\right)$ the after-audit limited liability constraint ${ }^{14}$ and by $(I C)$, the incentive compatibility constraint. ${ }^{15}$ With respect to other Principal-Agent models of optimal tax-enforcement policies, this last constraint incorporates the fact that, as a consequence of the imperfect detection technology, the auditing of taxpayers reporting $\widetilde{y}_{p}$ may result in type II errors: rich tax evaders are not identified as such. ${ }^{16}$ The government's budget constraint $\left(B^{\prime}\right)$ now incorporates the aggregate audit cost $(1-\mu) \pi_{p} c$ and the (sunk) cost of the initial investment $\kappa \cdot{ }^{17}$ As is usual in this kind of models, the fine $f_{r, p}$ does not enter in the maximand of the problem $\mathcal{P}_{2}$ because it only has a deterrent role.

At the optimum, $\left(L L_{r}^{\prime}\right)$ binds: increasing the fine $f_{r, p}$ up to its maximal legal level $y_{r}-t_{r}$ relaxes $(I C)$. Moreover, $(I C)$ also binds at the optimum: the government sets the audit strategy

$$
\pi_{p}=\frac{1}{\delta}\left(1-\frac{u\left(y_{r}-t_{r}\right)}{u\left(y_{r}-t_{p}\right)}\right)
$$

such that a potential evader is indifferent between truthfully reporting his income and misreporting. ${ }^{18}$ Observe another important difference with other Principal-Agent models of optimal tax-enforcement policies. At this stage, the government takes the detection

\footnotetext{
${ }^{14}$ As $f_{r, p} \geq 0$, imposing the after-audit limited liability constraint also ensures $t_{r} \leq y_{r}$.

${ }^{15}$ Since the number of taxpayers is very large, none of them considers the impact of non-complying with the tax law on the amount of public good. So $g$ does not appear in the incentive compatibility constraint.

${ }^{16} \mathrm{By}$ construction, this model does not generate type I errors, i.e. when a poor taxpayer is incorrectly identified as a rich by the tax administration. Although this type of mistakes occur in reality, the model abstract from them to address the most important problem the IRS faces. Indeed, according to IRS (2006), 50 percent of the total 2001 tax gap is attributed to undetected individual income tax underreporting.

${ }^{17}$ Without any loss of generality, we do not impose the net tax collection to be (weakly) positive because this should hold at the optimum. If this were not the case, it is straightforward to realize that not enforcing the tax law would dominate, making the net tax collection to be in fact strictly positive, as we will show below.

${ }^{18}$ Looking at (2), one may think that our model is just a rewriting of Besfamille and Parlatore Siritto's (2009) setting, with the probability of catching an evader $\zeta=\delta \pi_{p}$ playing the role of the audit probability $\pi_{p}$ that appears in the abovementioned article. Although this is true in terms of incentive-compatibility, it does not hold for all other dimensions. In particular, in order that our model be equivalent to the one analyzed by Besfamille and Parlatore Siritto (2009), the maximand of problem $\mathcal{P}_{2}$ should depend only upon $\zeta$ and $\kappa$. It is immediate to verify that there is no way to combine $\pi_{p}$ and $\delta$ so as to make this to happen.
} 
probability $\delta$ as a parameter. So nothing ensures that the value of $\pi_{p}$ that emerges from (2) satisfies ipso-facto the first constraint of the problem $\mathcal{P}_{2}$. Therefore, we have to analyze two different cases: random auditing $\left(\pi_{p}<1\right)$ and deterministic full auditing $\left(\pi_{p}=1\right)$.

Random auditing Neglecting momentarily the first constraint of the problem $\mathcal{P}_{2}$, we compute the first-order conditions under the random auditing regime $R^{A}$. Although we cannot verify analytically the second order conditions, we assume they hold and we focus our attention on the irst-order conditions because their interpretation will allow us to draw useful insights into the solution, insights that will be confirmed by the numerical example shown in Section 3.1.4. Rearranging the first-order conditions, we obtain the expressions that characterize an interior optimal tax schedule under random auditing $\left(t_{p}^{A}, t_{r}^{A}\right)$ :

$$
\left\{\begin{array}{l}
u_{q}\left(y_{r}-t_{r}^{A}\right)=\frac{1}{1+\frac{(1-\mu) c}{\delta \mu u\left(y_{r}-t_{p}^{A}\right)}}<1 \\
u_{q}\left(y_{p}-t_{p}^{A}\right)=1+\frac{u\left(y_{r}-t_{r}^{A}\right) u_{q}\left(y_{r}-t_{p}^{A}\right)}{\delta\left[u\left(y_{r}-t_{p}^{A}\right)\right]^{2}} c>1
\end{array}\right.
$$

In this case, taxpayer $i$ 's marginal utility of private consumption equals his marginal utility of the public good from $\partial g / \partial t_{i}^{A}$, the incremental increase in $g$ financed by a marginal increase in his corresponding tax $t_{i}^{A}$. Now, the rhs of both expressions in (3) differ because an identical marginal increase in both taxes does not affect the provision of public good $g$ in the same way. The reason for this is the following. Tax evasion modifies the cost of providing the public good because the tax administration has to audit low income reports. And it does so according to the frequency

$$
\pi_{p}^{A}=\frac{1}{\delta}\left(1-\frac{u\left(y_{r}-t_{r}^{A}\right)}{u\left(y_{r}-t_{p}^{A}\right)}\right)
$$

which depends positively (negatively) upon $t_{r}^{A}\left(t_{p}^{A}\right)$. Therefore, to save on audit costs, the government distorts the optimal tax schedule $\left(t_{p}^{A}, t_{r}^{A}\right)$ with respect to the optimal fullinformation tax schedule $\left(t_{p}^{*}, t_{r}^{*}\right)$. By concavity of the utility function $u()$, the distortions are clearly determined: $t_{p}^{A}>t_{p}^{*}$ and $t_{r}^{A}<t_{r}^{*}$. The next proposition characterizes the optimal tax law under random auditing. In particular, we explain how the optimal tax schedule $\left(t_{p}^{A}, t_{r}^{A}\right)$ and the optimal audit probability $\pi_{p}^{A}$ vary with the detection probability $\delta$.

Proposition 1 Let $\delta_{0}$ be the minimal detection probability compatible with auditing. If reports $\widetilde{y}_{p}$ are audited randomly, the optimal tax $t_{p}^{A}$ is a continuous and strictly decreasing function of $\delta$ that satisfies

$$
\lim _{\delta \rightarrow \delta_{0}^{+}} t_{p}^{A}=t_{0} \quad \text { and } \quad \lim _{\delta \rightarrow 1} t_{p}^{A}=\widetilde{t}_{p}>t_{p}^{*}
$$

On the other hand, the optimal tax $t_{r}^{A}$ is a continuous and strictly increasing function of $\delta$ that satisfies

$$
\lim _{\delta \rightarrow \delta_{0}^{+}} t_{r}^{A}=t_{0} \quad \text { and } \quad \lim _{\delta \rightarrow 1} t_{r}^{A}=\widetilde{t}_{r}<t_{r}^{*}
$$


The optimal audit probability $\pi_{p}^{A}$ is a continuous function of $\delta$ that satisfies

$$
\lim _{\delta \rightarrow \delta_{0}^{+}} \pi_{p}^{A}=0 \quad \text { and } \quad \lim _{\delta \rightarrow 1} \pi_{p}^{A}=\widetilde{\pi}_{p} .
$$

Under some parameter configurations of the model, $\pi_{p}^{A}$ increases with $\delta$, while under others it is non-monotonic.

When poor income reports are audited randomly, the optimal tax $t_{r}^{A}\left(t_{p}^{A}\right)$ is below (above) the optimal full-information tax $t_{r}^{*}\left(t_{p}^{*}\right)$ and increases (decreases) with the detection probability $\delta$. In order to understand why, let's assume first that audits are perfect, i.e. that $\delta=1$. The government sets the tax schedule $\left(\widetilde{t}_{p}, \widetilde{t}_{r}\right)$, charges the tax administration to audit with probability $\widetilde{\pi}_{p}^{19}$ and to impose to evaders the fine $\widetilde{f}_{r, p}=y_{r}-\widetilde{t}_{r}$, where $t_{p}^{*}<\widetilde{t}_{p}<\widetilde{t}_{r}<t_{r}^{*}$. Now consider a small decrease in the detection probability $\delta$. According to (2), $\pi_{p}$ increases ceteris paribus, and so does the aggregate audit cost $(1-\mu) \pi_{p} c$. This causes a decrease in the provision of the public good, and thus a direct welfare loss $\nabla W$. What should be the optimal reaction of the government? To increase the tax $t_{p}$ and the fine $f_{r, p}$, and to decrease the tax $t_{r}$, keeping the sum $t_{r}+f_{r, p}$ equal to $y_{r}$. Even if these changes reduce private consumption of the poor and may decrease further the provision of the public good, they have two other effects that attenuate the direct welfare loss $\nabla W$. First, the combined decrease in $t_{r}$ and increase in $t_{p}$ reduce the stake for evasion $S=u\left(y_{r}-t_{p}\right)-u\left(y_{r}-t_{r}\right)$, countering the initial increase of the audit probability. Second, reducing the tax $t_{r}$ makes private consumption of the rich to increase. Similar arguments can be used to explain why distortions $t_{r}^{*}-t_{r}^{A}, t_{p}^{A}-t_{p}^{*}$ increase when the detection probability $\delta$ decreases. Finally, for lower values of $\delta$, it becomes very difficult to detect evaders. Therefore, as audits are costly, the government optimally moves towards not enforcing the tax law. By incentive compatibility, both taxes $t_{p}^{A}, t_{r}^{A}$ should converge to the same level $t_{0}$.

Taking into account the optimal taxes and fine levels, we can obtain the profile of the expected welfare under regime $R^{A}$, denoted by $\mathbb{E} W^{A}$. When audits are random, $\mathbb{E} W^{A}$ increases with the detection probability $\delta$. By an envelope argument, a higher detection probability enables the government to reduce the aggregate audit cost, and thus to increase the provision of the public good.

Deterministic full auditing As mentioned above, deterministic full auditing cannot be ruled out as an optimal enforcement policy from the model. Indeed, under some parameter configurations, there exists an interval $\left[\delta_{1}, \delta_{2}\right]$, with $\delta_{0}<\delta_{1}<\delta_{2} \leq 1$, where $\pi_{p}=1$. Within such an interval, another audit regime, denoted by $R^{F A}$, obtains. There, the optimal tax schedule $\left(t_{p}^{F A}, t_{r}^{F A}\right)$ is characterized by the following expressions

$$
\left\{\begin{array}{l}
(1-\delta) \frac{u_{q}\left(y_{r}-t_{F}^{F A}\right)}{u_{q}\left(y_{r}-t_{r}^{F A}\right)}=\frac{(1-\mu)\left[u_{q}\left(y_{p}-t_{p}^{F A}\right)-1\right]}{\mu\left[1-u_{q}\left(y_{r}-t_{r}^{F A}\right)\right]} \\
\frac{u\left(y_{r}-t_{r}^{F A}\right)}{u\left(y_{r}-t_{p}^{F A}\right)}=1-\delta
\end{array}\right.
$$

\footnotetext{
${ }^{19}$ We assume that the parameters of the model ensure that $0<\widetilde{\pi}_{p}<1$.
} 
As the aggregate audit cost is constant, the government considers the gross tax collection $\mu t_{r}+(1-\mu) t_{p}$ as a proxy for the public good provision when it decides marginal changes in the tax schedule. At the optimum, the government set taxes to equalize the marginal rate of tax variations consistent with deterministic full auditing (the lhs of the first expression in (4), which is the value of $d t_{r} /\left.d t_{p}\right|_{\pi_{p}^{F A=1}}$ ) to the social marginal rate of substitution (the rhs, which is the ratio of marginal changes in individual welfares, with their corresponding social weights). The next proposition characterizes the optimal tax schedule under full auditing.

Proposition 2 If all reports $\widetilde{y}_{p}$ are audited, the optimal tax $t_{p}^{F A}$ is a continuous and strictly decreasing function of $\delta$, that satisfies $t_{p}^{F A}>t_{p}^{A}$. On the other hand, the optimal tax $t_{r}^{F A}$ is a continuous and strictly increasing function of $\delta$, that satisfies $t_{r}^{F A}<t_{r}^{A}$.

Under deterministic full auditing, taxes vary with $\delta$ in the same way as under random auditing. But, as their variations are constrained, the difference $t_{r}^{F A}-t_{p}^{F A}$ is, for a given $\delta \in$ $\left[\delta_{1}, \delta_{2}\right]$, lower than the same difference that would have emerged if $\pi_{p}$ were not constrained to be lower than unity.

Taking into account the optimal taxes and fine levels, we can obtain the profile of the expected welfare under regime $R^{F A}$, denoted by $\mathbb{E} W^{F A}$. Again, when all reports are audited, $\mathbb{E} W^{F A}$ increases with the detection probability $\delta$. A higher detection probability enables the government to reduce the tax distortions $t_{r}^{*}-t_{r}, t_{p}-t_{p}^{*}$.

\subsubsection{The no audit regime}

When the detection probability $\delta$ is relatively low, the government gives up enforcing the tax law, i.e. it sets $\pi_{p}=0$. We denote this regime by $R^{N A}$. In this case, assuming -as we do- that there may exist honest taxpayers becomes very relevant. When all rich taxpayers are dishonest $(\theta=1)$, the government collects taxes $t_{0}$ from all taxpayers. But when there are some honest rich taxpayers, no matter how few $(\theta<1)$, the government can collect higher taxes from them. In this case, there is no complete revelation of individual types. ${ }^{20}$ The government does not have enough instruments to screen between honest and dishonest rich taxpayers, so the latter misreport and thus evasion occurs. Taking into account this, the government solves

$$
\mathcal{P}_{3}\left\{\begin{array}{l}
\underset{t_{p}, t_{r}, g}{\operatorname{Max}} \mu\left[(1-\theta) u\left(y_{r}-t_{r}\right)+\theta u\left(y_{r}-t_{p}\right)\right]+(1-\mu) u\left(y_{p}-t_{p}\right)+g \\
\text { subject to } \\
g=[1-\mu(1-\theta)] t_{p}+\mu(1-\theta) t_{r}
\end{array}\right.
$$

The objective function is similar to the full-information maximand. Therefore, the government sets the optimal tax schedule $\left(t_{p}^{N A}, t_{r}^{N A}\right)$ characterized by the following expressions

$$
\left\{\begin{array}{l}
u_{q}\left(y_{r}-t_{r}^{N A}\right)=1 \\
(1-\mu) u_{q}\left(y_{p}-t_{p}^{N A}\right)+\mu \theta u_{q}\left(y_{r}-t_{p}^{N A}\right)=1-\mu(1-\theta)
\end{array} .\right.
$$

\footnotetext{
${ }^{20}$ For similar results, albeit in different contexts, see Kofman and Lawarrée (1996) and Picard (1996).
} 
As total welfare is quasi-linear in the public good, the government does not need to distort, with respect to the full-information level, the tax owed by honest rich taxpayers. But this is not the case for the other tax. Assume for the moment that $t_{p}^{N A}=t_{p}^{*}$. As dishonest rich taxpayers that evade have a lower marginal utility of private consumption than poor taxpayers (i.e. $u_{q}\left(y_{r}-t_{p}^{*}\right)<1$ ), the second expression in (5) would not be satisfied: the social marginal utility of individuals paying $t_{p}^{*}$ would be lower than their social marginal utility of the public good. Therefore, to restore optimality, the government increases $t_{p}$ : it taxes more the dishonest rich, but also the poor. Clearly, the values of $t_{p}^{N A}$ and $t_{r}^{N A}$ depend upon the fraction of dishonest rich taxpayers. The next proposition clarifies this statement.

Proposition 3 When reports $\widetilde{y}_{p}$ are no audited, the optimal tax $t_{p}^{N A}$ increases with the fraction of dishonest rich taxpayers $\theta$, satisfying

$$
\lim _{\theta \rightarrow 0} t_{p}^{N A}=t_{p}^{*} \quad \text { and } \quad \lim _{\theta \rightarrow 1} t_{p}^{N A}=t_{0} .
$$

The optimal tax $t_{r}^{N A}$ only adopts two values: either $t_{r}^{N A}=t_{r}^{*}$ when $\theta<1$; otherwise, $t_{r}^{N A}=t_{0}$.

The higher the proportion of dishonest among the rich taxpayers is, the bigger would be the abovementioned gap between the social marginal utility of private consumption and the social marginal utility of the public good of those paying the (assumed) tax $t_{p}^{*}$. Therefore, the bigger should the increase in the tax $t_{p}$ needed to restore optimality be. Regarding the other tax, as soon as a fraction of rich is honest, $t_{r}^{N A}=t_{r}^{*}$. But when $\theta=1$ there is a discontinuity: the tax jumps downward to $t_{0}$.

\subsubsection{The choice of the audit regime}

Naturally, the government will choose a tax law leading to the regime that generates the highest expected welfare. The following proposition completely characterizes this choice.

Proposition 4 There exists a threshold $\underline{\delta}$, implicitly defined by

$$
\mathbb{E} W^{N A}=\max \left\{\mathbb{E} W^{A}(\underline{\delta}), \mathbb{E} W^{F A}(\underline{\delta})\right\},
$$

and verifiying $\delta_{0} \leq \underline{\delta} \leq 1$, that separates regimes with and without auditing. When $\delta \geq \underline{\delta}$, the government designs a tax law that will be enforced afterwards. The opposite holds when $\delta<\underline{\delta}$.

When there are honest taxpayers and the government does not audit, the expected welfare $\mathbb{E} W^{N A}$ is higher than $\mathbb{E} W^{A}\left(\delta_{0}\right)$ because the former is reached taxing differently rich and poor individuals, whereas the latter is attained when the government does not discriminate between taxpayers. As $\mathbb{E} W^{A}$ and $\mathbb{E} W^{F A}$ increase with $\delta$, it is straightforward to show that there exists a threshold $\underline{\delta}>\delta_{0}$ that separates regimes with and without auditing. When all rich taxpayers are dishonest, the government cannot tax differently under regime $R^{N A}$. Therefore, the minimal detection probability compatible with auditing $\delta_{0}$ becomes the pertinent threshold. ${ }^{21}$

${ }^{21}$ When $\theta=1, \mathbb{E} W^{N A}=\mathbb{E} W^{A}\left(\delta_{0}\right)$. 


\subsubsection{A numerical example}

We provide now a numerical example to illustrate these results. The retained utility function is

$$
u(q)=\frac{q^{1-\sigma}}{1-\sigma},
$$

with $\sigma=0.71$. The other parameters are $y_{p}=\$ 6.747, y_{r}=\$ 52.304, \mu=0.67, \theta=0.36$ and $c=\$ 14.833$. The choice of these values will be explained in detail in Section 4 . The results are shown in Figures 1 below, where the endogenous variables of the second stage of the model are plotted as functions of the detection probability $\delta$.

The figures show that, under this retained parameter configuration of the model, the three regimes emerge. When $\delta \leq \underline{\delta}=0.38$, the government designs a tax law that will not be enforced by the tax administration. Under regime $R^{N A}, t_{p}^{N A}=\$ 6.27$ and $t_{r}^{N A}=\$ 51.3$. Then, for values of the detection probability higher than 0.38 , the government designs an enforceable tax law. But, as the audit cost is relatively low, as soon as $\delta>\underline{\delta}$, all reports $\widetilde{y}_{p}$ are audited, as we can observe in Figure 1(c) So both taxes jump downward, to $t_{p}^{F A}=\$ 6.06$ and $t_{r}^{F A}=\$ 43.46$, respectively. Then, as $\delta$ increases, taxes vary as expected. When $\delta=0.50$, as the detection probability is sufficiently high, the tax administration starts auditing randomly poor reports and thus regime $R^{A}$ emerges. Then, as $\delta$ increases, the tax $t_{p}^{A}\left(t_{r}^{A}\right)$ decreases (increases), but at a lower rate than under full-auditing. Therefore, as the increase in $\delta$ exceeds the increase in the rich's stake for evasion $S$, the optimal audit probability $\pi_{p}^{A}$ decreases. Finally, when $\delta=1, t_{p}^{A}=\$ 5.81, t_{r}^{A}=\$ 49.86$ and $\pi_{p}^{A}=0.57$.
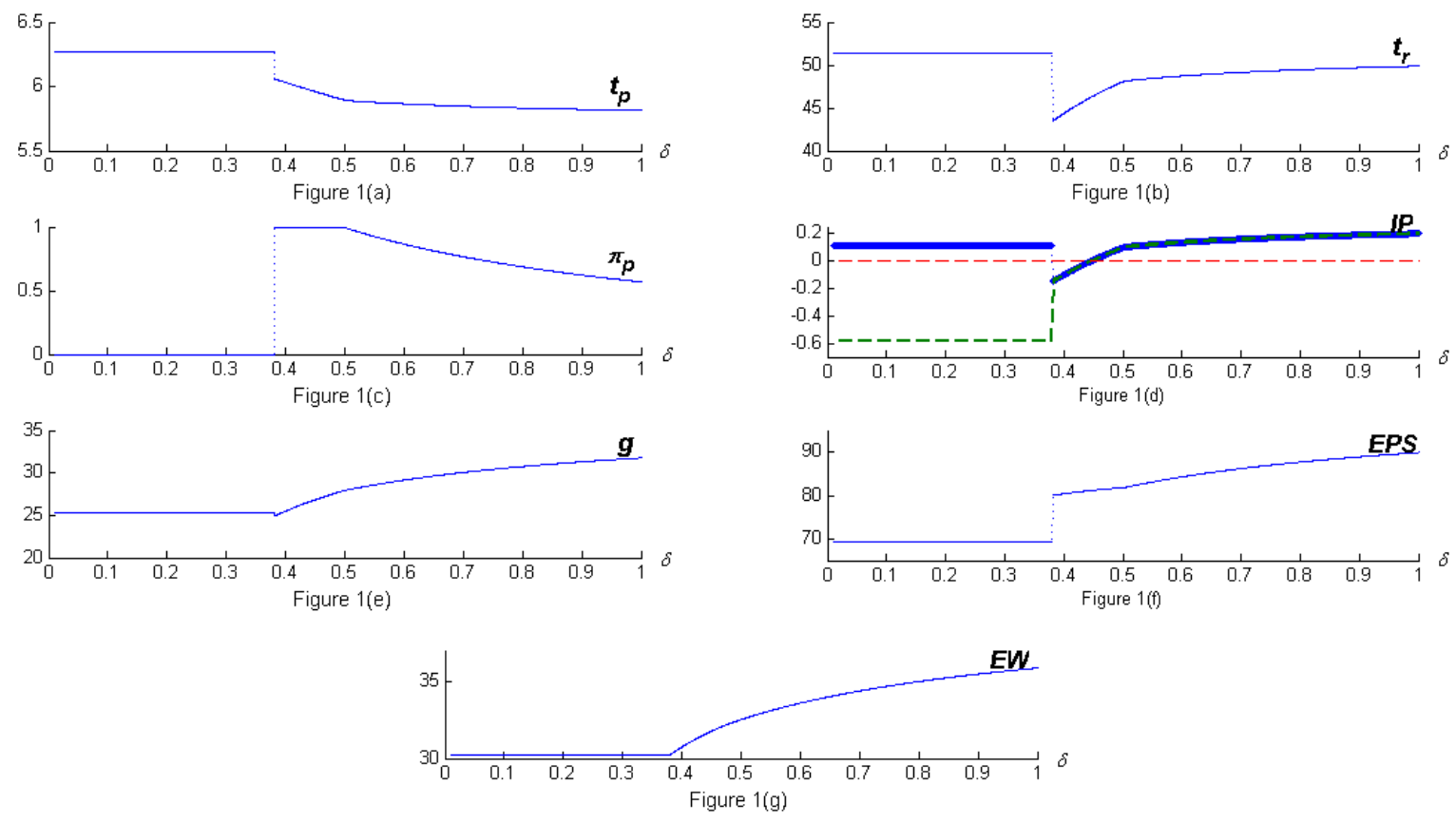

Figures 1: The second stage outcomes

These changes in the tax law have the following consequences. First, to consider the 
progressivity of the tax structure as a whole, let's analyze the index

$$
I P=\frac{\tau_{r}-\tau_{p}}{y_{r}-y_{p}}
$$

where $\tau_{i}=t_{i} / y_{i}$ is the average tax payment (in percent of the income) of individual $i$. $I P$ measures the percent variation of the average tax payment, for each $\$ 1,000$ increase in income. When $I P>0$, the tax structure is progressive, and higher values of $I P$ denote higher progressivity. When $I P<0$, the tax structure is regressive, and the lower the value of $I P$, the higher the regressiveness. Figure $1(\mathrm{~d})$ depicts the values adopted by $I P$. Under regime $R^{N A}$, the tax system is legally progressive: as $\tau_{p}^{N A}=t_{p}^{N A} / y_{p}=93$ percent $<\tau_{r}^{N A}=t_{r}^{N A} / y_{r}=98$ percent, $I P=0.11$ percent. But, as some rich individuals are indeed taxed as poor, the effective average tax payment for rich individuals amounts to $\theta t_{p}^{N A}+(1-\theta) t_{r}^{N A} / y_{r}=66$ percent. Hence, the index of progressivity is indeed $I P=$ -0.59 percent. This is depicted as a dashed line in the figure, clearly below the bold line representing the legal index. So, in fact, under regime $R^{N A}$, the tax system is effectively regressive. When $\delta=0.38$ and regime $R^{F A}$ emerges, the distinction between legal and effective progressivity disappears. The situation improves slightly: as $\tau_{p}^{F A}=90$ percent and $\tau_{r}^{F A}=83$ percent, $I=-0.15$ percent. Nevertheless, the tax system remains regressive over a range of values of $\delta$. Only when $\delta=0.45$, average tax payments $\tau_{p}^{F A}$ and $\tau_{r}^{F A}$ are equal to 88 percent, and thus $I=0$. From this value of the detection probability onwards, the tax system becomes increasingly progressive.

Second, the provision of the public good is non-monotonic, as observed in Figure 1(e). Under regime $R^{N A}, g=25.28$. When $\delta=0.38, g$ jumps downward to 24.90. The reason for this slight decrease relies upon the fact that, when regimes change, both taxes jump downward and the audit probability jumps upward. Therefore, and despite the fact that the tax administration now collects taxes $t_{r}^{F A}$ from all rich, and not only from the honest (as it was the case under regime $R^{N A}$ ), the net tax collection jumps downward. Then, as $\delta$ increases, $g$ increases, to reach finally 31.75 .

Third, Figure 1(f) illustrates the efficiency of the public sector EPS. This percentage measures how much of the potential tax collection is used to provide the public good. Under regime $R^{N A}, E P S=69.37$ percent. The more than 30 percent of inefficiency is due to tax evasion. When $\delta=0.38$, this percentage jumps upward, to 80 percent. The government ends up delivering a higher fraction of the tax collection as a public good because, despite the downward jump in $g$, the tax collection decreases more in relative terms. Under regimes $R^{A}$ or $R^{F A}$, the degree of 'inefficiency' comes from the need to use public resources to invest in the tax administration and to enforce the tax law. Then, when $\delta$ increases, EPS monotonically increases, to reach 89.9 percent when audits are perfect. Observe that the rate of increase is higher under regime $R^{A}$ than under regime $R^{F A}$.

Finally, Figure $1(\mathrm{~g})$ shows that expected welfare amounts to 30.25 under regime $R^{N A}$. When the government starts enforcing the tax law, the expected welfare does not jump: the welfare improving decrease in the regressiveness of the tax system counters exactly the social desutility caused by the downward jump in $g$. Therefore, from $\underline{\delta}=0.38$, the expected welfare increases monotonically with the detection probability, to reach 35.86 when $\delta=1$. 


\subsection{The optimal investment}

Now we move back to the first stage of the model. Anticipating its future fiscal choices, the government decides to invest to improve the tax administration's capacity to detect evaders. This decision has two different impacts. On the one hand, it affects the expected social welfare because the government allocates tax revenues to investment $\kappa$, instead of using them to provide the public good $g$. On the other hand, as investment changes the value of the detection probability $\delta$, this decision can also fix under which regime the government will design the tax law in the second stage. In order to address the choice of regime in terms of the variable $\kappa$, let $\underline{\kappa}$ denote the implicit solution of the equation $\delta(\kappa, \nu)=\underline{\delta} \cdot{ }^{22}$ The expected welfare can now be written as a function of investment $\kappa$, as follows

$$
\begin{array}{ll}
\text { if } \delta_{\iota} \geq \underline{\delta} \quad \mathbb{E} W=\max \left\{\mathbb{E} W^{A}, \mathbb{E} W^{F A}\right\} & \text { for } \kappa \geq 0 \\
\text { if } \delta_{\iota}<\underline{\delta} \quad \mathbb{E} W= \begin{cases}\mathbb{E} W^{N A} & \text { for } \kappa=0 \\
\max \left\{\mathbb{E} W^{A}, \mathbb{E} W^{F A}\right\} & \text { if } \kappa \geq \max \{0, \underline{\kappa}\}\end{cases}
\end{array}
$$

As we can see, the value of the initial detection probability $\delta_{\iota}$ is important to characterize the expected welfare. When $\delta_{\iota} \geq \underline{\delta}$, only audit regimes emerge. But this is not the case when $\delta_{\iota}<\underline{\delta}$ : depending upon the level of investment $\kappa$, all regimes can obtain. The fact that $\kappa=0$ under regime $R^{N A}$ incorporates the result that the government does not invest to improve the detection probability, because it anticipates not auditing.

In order to solve for the optimal investment $\widehat{\kappa}$, we proceed as follows. First, we find $\kappa^{A}$ and $\kappa^{F A}$, the levels that maximize $\mathbb{E} W^{A}$ and $\mathbb{E} W^{F A}$, respectively. Second, when it is pertinent to do so, we compare $\left\{\mathbb{E} W^{A}\left(\kappa^{A}\right), \mathbb{E} W^{F A}\left(\kappa^{F A}\right)\right\}$ with $\mathbb{E} W^{N A}$ to take the overall $\operatorname{maximum} \widehat{\kappa}$.

Under the random auditing regime $R^{A}$, the optimal investment $\kappa^{A}$ solves the following problem

$$
\mathcal{P}_{1}^{A}\left\{\begin{array}{l}
\underset{\kappa}{\operatorname{Max}} \quad \mu\left[u\left(y_{r}-t_{r}^{A}\right)+t_{r}^{A}\right]+(1-\mu)\left[u\left(y_{p}-t_{p}^{A}\right)+t_{p}^{A}\right]-(1-\mu) \pi_{p}^{A} c-\kappa \\
\text { subject to } \\
\delta=\delta(\kappa, \nu) \\
\max \{0, \underline{\kappa}\} \leq \kappa \\
\kappa \leq \mu t_{r}^{A}+(1-\mu) t_{p}^{A}-(1-\mu) \pi_{p}^{A} c
\end{array}\right.
$$

where $\pi_{p}^{A}, t_{p}^{A}$ and $t_{r}^{A}$ are given by (2) and (3), respectively. In the maximand, $g$ has been replaced by its corresponding value in the government's budget constraint. From Proposition 1, these variables are uniquely defined and continuous functions of the detection probability $\delta$. The last two inequalities characterize the constraint set. The first inequality reflects that the lowest value of $\kappa$ supporting regime $R^{A}$ is not unique because it depends

\footnotetext{
${ }^{22}$ We also denote by $\kappa_{1}, \kappa_{2}$ the solution of $\delta(\kappa, \nu)=\kappa_{1}, \kappa_{2}$, respectively. Given the properties of the function $\delta(), \underline{\kappa}, \kappa_{1}$ and $\kappa_{2}$ are unique.
} 
upon the initial level $\delta_{\iota}$, as it is clear from (6). The second inequality shows the resource constraint of the government, at this initial stage.

A general characterization of the solution to the problem $\mathcal{P}_{1}^{A}$ is difficult, for the following reasons. First, when $\max \{0, \underline{\kappa}\}=\underline{\kappa}$, the constraint set may be empty. Indeed, under some parameter configurations of the model (e.g. high audit cost c), no investment $\kappa \geq \underline{\kappa}$ fulfills the resource constraint. Second, even if the constraint set is non empty and thus we know that the problem $\mathcal{P}_{1}^{A}$ has a maximum, ${ }^{23}$ it is often difficult to find it with the usual techniques because the expected welfare $\mathbb{E} W^{A}$ is not always concave in $\kappa$ and the second-order condition, evaluated at the critical points, cannot be verified analytically. ${ }^{24}$ Despite this fact, as we did in the previous section, we present and analyze the first-order condition that characterizes an interior optimum $\kappa^{A}$, as follows

$$
-(1-\mu) \frac{\partial \pi_{p}^{A}}{\partial \delta} \delta_{\kappa} c=1
$$

where $\partial \pi_{p}^{A} / \partial \delta=-\pi_{p}^{A} / \delta$. The lhs of this expression is the marginal benefit of increasing investment, and the rhs, its marginal cost (hereinafter MCI), which is always equal to 1. By an envelope argument, the marginal benefit is formed as the product of the effect of an increase in the detection probability on the aggregate audit cost $\left(-(1-\mu) . \partial \pi_{p}^{A} / \partial \delta . c\right)$ and the detection improvement due to a marginal increase in $\kappa\left(\delta_{\kappa}\right)$. This product measures savings in the aggregate audit cost that obtain from a marginal increase in $\kappa$. Consequently, we denote by MSAAC the lhs of (7).

Under the deterministic full auditing regime $R^{F A}$, the optimal investment $\kappa^{F A}$ solves the following problem

$$
\mathcal{P}_{1}^{F A}\left\{\begin{array}{l}
\underset{\kappa}{M a x} \quad \mu\left[u\left(y_{r}-t_{r}^{F A}\right)+t_{r}^{F A}\right]+(1-\mu)\left[u\left(y_{p}-t_{p}^{F A}\right)+t_{p}^{F A}\right]-(1-\mu) c-\kappa \\
\text { subject to } \\
\pi_{p}^{F A}=1 \\
\delta=\delta(\kappa, \nu) \\
\kappa_{1} \leq \kappa \leq \kappa_{2} \\
\kappa \leq \mu t_{r}^{F A}+(1-\mu) t_{p}^{F A}-(1-\mu) c
\end{array}\right.
$$

where $t_{p}^{F A}$ and $t_{r}^{F A}$ are given by (4) and are uniquely defined continuous functions of the detection probability $\delta$. The last two inequalities characterize the constraint set. For the

\footnotetext{
${ }^{23}$ When the constraint set is non empty, it is bounded from below by 0 , and from above by the fullinformation tax collection $\mu t_{r}^{*}+(1-u) t_{p}^{*}$. Moreover, this set is also closed because it is defined by weak inequalities and the functions $t_{p}^{A}, t_{r}^{A}$ and $\pi_{p}^{A}$ are continuos in $\delta$, thus in $\kappa$. Hence, the constraint set is compact. In addition, the maximand in $\mathcal{P}_{1}^{A}$ is also continuos in $\kappa$. So, by the Weierstrass theorem (see Takayama 1985), the problem $\mathcal{P}_{1}^{A}$ has a maximum.

${ }^{24}$ Investment $\kappa$ impacts the expected welfare $\mathbb{E} W^{A}$ in many different ways: (i) directly: through the budget constraint of the government, and (ii) indirectly: through $\delta$ and the optimal values of $t_{p}^{A}, t_{r}^{A}$ and $\pi_{p}^{A}$, whose relation with $\kappa$ depends upon the retained functional specification of $u()$ and $\delta()$. But, as there are no convincing arguments (neither theoretical nor empirical) for any specific form of $u($ ) or $\delta()$, the concavity of the expected welfare $\mathbb{E} W^{A}$ is, in fact, a numerical question. Hence, we can always find specifications of these two functions such that $\mathbb{E} W^{A}$ is not globally concave.
} 
same reasons mentioned above, a general characterization of the solution to the problem $\mathcal{P}_{1}^{F A}$ is difficult. Assuming an interior solution, the optimal investment $\kappa^{F A}$ is given by the following expression

$$
\mu\left[1-u_{q}\left(y_{r}-t_{r}^{F A}\right)\right] \frac{\partial t_{r}^{F A}}{\partial \delta} \delta_{\kappa}+(1-\mu)\left[1-u_{q}\left(y_{p}-t_{p}^{F A}\right)\right] \frac{\partial t_{p}^{F A}}{\partial \delta} \delta_{\kappa}=1
$$

As $\pi^{F A}=1$, the aggregate audit cost is fixed. Thus, an increase in $\kappa$ has a marginal benefit only through a change in the values of the optimal tax schedule $\left(t_{p}^{F A}, t_{r}^{F A}\right)$. But now, this schedule is determined by the expressions in (4), and not by first-order conditions like in (3). Therefore, one cannot apply an envelope argument, as it was the case for the intuition of the first-order condition (7). Now, the marginal benefit of an increase in $\kappa$ (the lhs of (8)) is formed as the sum of two products: the effect of an increase of each tax on the gross expected welfare $\left(\mu\left[1-u_{q}\left(y_{r}-t_{r}^{F A}\right),(1-\mu)\left[1-u_{q}\left(y_{p}-t_{p}^{F A}\right)\right]\right)\right.$ and the effect of a marginal increase in investment on each optimal tax $\left(\frac{\partial t_{r}^{F A}}{\partial \delta} \delta_{\kappa}, \frac{\partial t_{P}^{F A}}{\partial \delta} \delta_{\kappa}\right)$. Consequently, we call 'marginal increase in the gross expected welfare' (MIGRW) the lhs of (8). At the optimum, the government equalizes MIGEW to MCI.

Finally, even if one succeeds in identifying $\kappa^{A}$ and $\kappa^{F A}$, the comparison between $\mathbb{E} W^{N A}$, $\mathbb{E} W^{A}\left(\kappa^{A}\right)$ and $\mathbb{E} W^{F A}\left(\kappa^{F A}\right)$ is not straightforward because it is a comparison of levels. All these analytic difficulties push us to simulate the model in the next section.

\section{Numerical simulations}

\subsection{Baseline parameters}

In this section, we simulate numerically the model for parameter values representative of the US tax system and the IRS's operations in 2006. These simulations ${ }^{25}$ help us in several ways: to identify parameter configurations under which the government does invest to improve the tax administration's detection probability; in this case, to quantify the other components of the optimal fiscal policy, and finally to obtain comparative statics results. ${ }^{26}$ Throughout these simulations, all money amounts are in thousands of dollars. We adopt the following functional and parameter specifications.

As in Mookherjee and Png (1990) and Pestieau, Possen and Slutsky (2004), taxpayers are characterized by a CRRA utility function, as follows

$$
u(q)=\frac{q^{1-\sigma}}{1-\sigma},
$$

where $\sigma>0$ is the coefficient of relative risk aversion. To be consistent with one of the assumptions of the model (i.e. $u(0)=0$ ), we need to impose another restriction on this parameter: $\sigma<1$. As there is no theoretical or empirical consensus about $\sigma$, we assume

\footnotetext{
${ }^{25}$ The simulations have been done with Matlab 7.0. All codes and results are available upon request from the authors.

${ }^{26}$ Even if one assumes interior optimal investments $\kappa^{A}, \kappa^{F A}$, almost all comparative statics produce ambiguous analythic results.
} 
that $\sigma=0.71$, the value obtained by Chetty (2006). Then, in the sensitivity analysis, we let $\sigma$ to vary between 0.15 and 1 . The first value represents the lowest estimation of $\sigma$ referenced in Chetty (2006); the highest value is the abovementioned upper bound.

We adopt the following strategy to determine the parameters that characterize the income distribution. To begin with, the set of individuals that have filled in income tax returns in 2006 represents the population of taxpayers. Among them, 67 percent filled in taxable tax returns (IRS 2007b). This percentage will be the fraction $\mu$ of rich taxpayers. According to Bryan (2008), their average income was $\$ 52.304$. We take this value to be $y_{r}$. Next, in order to obtain the poor's income, we proceed as follows. First, for each filling status ${ }^{27}$ we compute the minimum taxable income, i.e. the level of income that determines whether an income return is taxable or not. ${ }^{28}$ Second, we use the percentage of non-taxable returns within each filling status as weights to compute the average minimum taxable income, which amounts to $\$ 12.216$. Then we look at the Statistical Abstract of the United States (US Bureau of the Census 2009) to compute the average income of those individuals that have earned less than this amount in 2006. This figure represents $y_{p}$ and is equal to $\$ 6.747$. In the comparative statics, $y_{p}$ will adopt values between $\$ 0$ and $\$ 52.304$ (the baseline value of the rich's income); and $y_{r}$, between $\$ 6.747$ (the baseline value of the poor's income) and $\$ 100$ (almost the double of its baseline value). Finally, $\mu$ will vary between 0 and 1.

Although it is now accepted that moral considerations do have an impact on individual and aggregate tax compliance, quantifying them is really difficult. In order to have at least an estimate for the parameter $\theta$, we use the results of the US Values Survey (2006), which collected responses to scores of questions from 1,710 adults. In the chapter on social misbehaviors, people were specifically asked whether they think if "Cheating on taxes if you have a chance" it can always be justified, never justified, or something in between. As a result, 64 percent of respondents declared that tax evasion is never justified. Therefore, we assume that $\theta=0.36 .{ }^{29}$ As for the fraction $\mu$, we will let $\theta$ to vary between 0 and 1 .

Individual taxpayers can face two kinds of audits: field (face-to-face) or correspondence audits. In these simulations, we assume that audits are only of the first type. Thus, as the cost of a single audit is not publicly available, we have to estimate the parameter $c$. We proceed as follows. During the fiscal year 2006, IRS total expenditures in tax law enforcement (TEE) were $\$ 4,651,150$. These total expenditures can be decomposed into two items: personnel compensations $(P C)$, which amount to $\$ 4,244,896$ and other expenditures $(O E)$, to $\$ 406,254$ (IRS Data Book 2006). Regarding personnel compensations, we postulate the following cost relation:

$$
P C=c_{c} \cdot x_{c}+c_{f} \cdot x_{f}
$$

where $c_{c}\left(c_{f}\right)$ is the cost of a single correspondence (field) audit and $x_{c}\left(x_{f}\right)$, the number of

\footnotetext{
${ }^{27}$ The five filling status are: single, head of household, married filling jointly, married filling separately and qualifying widow(er) with dependent child.

${ }^{28}$ For each filling status, there is a minimum taxable income per range of age of the filler(s). We take the simple average between these figures to be the minimum taxable income per filling status.

${ }^{29}$ The method of collection could be criticized. The interviews were face to face, which introduces a bias, since people might have different answers to some questions if they could answer anonymously. Moreover, the answers may also depend upon the IRS's enforcement strategy, which poses a problem of endogeneity. Despite these drawbacks, we proceed in the way described in the text.
} 
correspondence (field) audits performed. Within the fiscal year 2006, the IRS conducted 981,165 correspondence examinations and 302,785 field audits. ${ }^{30}$ Next, we estimate the cost of a single field audit relative to the cost of a correspondence examination, in terms of the time necessary to conduct such audits. According to the General Accounting Office (1999), the time spent by the IRS staff averaged 0.8 hours per corresponding examination. On the other hand, anecdotal evidence suggests that a field audit can last 1 day to 2 weeks (Herman 2007). Assuming that a field audit lasts 5 working days (40 hours) on average, its duration is 50 times longer than the duration of a correspondence audit. Moreover, according to the (online) Federal government's official job list (www.USAjobs.gov), the wage of a revenue agent that conducts field audits is, on average, 2.47 times higher than the salary of a revenue officer, in charge of correspondence examinations. Therefore, $c_{f}$ ends up being 123.5 times more than $c_{c}$. Replacing this estimation in (9), we obtain that $c_{c}=\$ 0.111$, and so $c_{f}=\$ 13.71$. Then, we allocate the other expenditures $O E$ and the Information systems expenditures $(\$ 902,067,422)^{31}$ between correspondence and field audits based on their actual usage. As field audits represent 23.6 percent of all examinations, the amount of additional expenditures allocated to them reaches $\$ 340,163.460$. Dividing this amount by the number of field audits gives $\$ 1.123$ per audit. Finally, summing this last amount to $c_{f}$ gives the estimate $c=\$ 14.833$. We will let $c$ to vary between $\$ 3.306$ and $\$ 33$. The lower bound represents the average cost of an IRS's audit, obtained by dividing the entire budget of the enforcement division by the total number of audits conducted in 2006. The upper bound is ten times the lower bound. Proceeding in that way, the baseline value is below the average of the two bounds.

Finally, nothing is known with respect to the detection probability function. A convenient formulation is the logistic function, as follows

$$
\delta(\kappa, \nu)=\delta_{\iota}+\nu \frac{1-e^{-\frac{\kappa}{a}}}{1-n e^{-\frac{\kappa}{a}}} .
$$

In order to focus on the impact that investments have upon detection, we assimilate $\delta_{\iota}$ to the actual IRS's detection probability. As mentioned in the Introduction, there have been some estimations about this probability. Feinstein (1991) concludes that IRS's inspectors find one of two dollars evaded. Recently, Erard and Feinstein (2010) obtain, using data of 2001, an average detection rate of 32 percent. We assume that $\delta_{\iota}=0.4$, approximately the average of these two estimations, and we will let $\delta_{\iota}$ to vary between them. As for the other baseline parameters, we adopt $a=0.235, n=0.99$ and $\nu=0.225$. With these parameters,

\footnotetext{
${ }^{30}$ Although some of these audits examined returns filled within previous fiscal years, we assume that they only concern 2006 returns.

${ }^{31}$ Information systems expenditures were $\$ 1,684.533$ in 2006 . We allocate $\$ 902,067.422$ to tax law enforcement, according to the share of this activity (53.55 percent) in the total IRS's budget.
} 
the detection probability function has the following shape, shown in Figure 2.

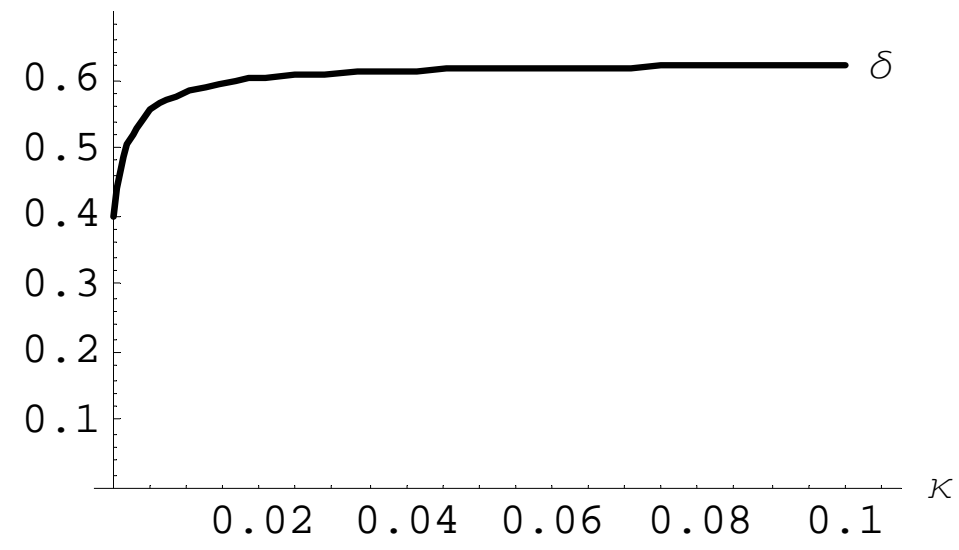

Figure 2: Detection probability function

We believe that this concave curve illustrates the (supposed) cost-effectiveness of CADE, the IRS project described in the Introduction. By 2008, the IRS has invested over $\$ 400$ million in this project, that has delivered about 15 percent of the full capability intended (General Accounting Office, 2008). We extrapolate this number, which gives a total cost for CADE of $\$ 2.67$ billion, or nearly $\$ 20$ per taxpayer. Although no quantitative information exists about the impact that CADE can have on the current detection probability, we postulate that it will enable to increase the detection probability by 50 percent, from $\delta_{\iota}=0.4$ to $0.6 .^{32}$ In the comparative statics, the investment productivity will vary between 0 and 0.6. This last value ensures that the detection probability is always below one.

Table 1 gathers the most important parameter values of the model and their variation's range

\begin{tabular}{|c|c|c|c|}
\hline PARAMETER & DEFINITION & BASELINE VALUE & RANGE \\
\hline$\sigma$ & Coefficient of relative risk aversion & 0.71 & {$[0.15,1[$} \\
\hline$\mu$ & Percentage of rich taxpayers & 67 & {$[0,1]$} \\
\hline$y_{r}$ & Income of the rich & $\$ 52.304$ & {$[\$ 6.747, \$ 100]$} \\
\hline$y_{p}$ & Income of the poor & $\$ 6.747$ & {$[\$ 0, \$ 52.304]$} \\
\hline$\theta$ & Percentage of dishonest taxpayers & 36 & {$[0,1]$} \\
\hline$c$ & Cost of a single audit & $\$ 14.833$ & {$[\$ 3.306, \$ 26.36]$} \\
\hline$\delta_{\iota}$ & Initial detection probability & 0.4 & {$[0.3,0.5]$} \\
\hline$\nu$ & Investment productivity & 0.225 & {$[0,0.6]$} \\
\hline
\end{tabular}

Table 1: Parameter values of the model

\footnotetext{
${ }^{32}$ The project CADE has been undertaken to improve not only the IRS's detection capacity but also other dimensions of its activity (e.g. taxpayers' services). Therefore it may seem exaggerated to allocates CADE's cost exclusively to the former objective. Despite this fact, as it is hard to know the fraction of CADE's cost to allocate to each objective, we prefer to maintain the retained assumption.
} 


\subsection{Optimal fiscal policy}

With these baseline parameters, we obtain the equilibrium values of the model. Consider first a government that cannot invest, and thus its tax administration's detection probability is $\delta_{\iota}$. Under this circumstance, the optimal fiscal policy is characterized by $t_{p}=\$ 6.03, t_{r}=$ $\$ 44.35, \pi_{p}=1$ and $g=\$ 26.81$. As $\tau_{r}=85$ percent $<\tau_{p}=89$ percent, $I P=-0.087:$ the tax structure is regressive. Due to individual's welfare being quasi-linear in the public good and to the CRRA specification of the utility function $u(q)$, individuals end up facing quite high average tax payments throughout these simulations. But they are compensated with an important provision of public good. Finally, the efficiency of the public sector reaches 85.3 percent.

Next, assume that the government has the option to invest. At the optimum, it chooses $\widehat{\kappa}=\$ 0.059$, and thus the detection probability $\delta$ increases 55 percent, from 0.4 to 0.62 . As expected, the other components of the optimal fiscal policy change: $\widehat{t}_{p}=\$ 5.83$ (a 2.9 percent reduction) and $\widehat{t}_{r}=\$ 47.4$ (a 6.9 percent increase). The last result contradicts the assertion, often made in administrative and political circles, that if investments that help to improve tax compliance were made, the highest marginal tax rates could be cut. The reason why this is not true in our case is the following. When the government cannot invest, the highest tax $t_{r}$ was set at a 'relatively' low level, to attenuate the rich's stake for evasion. But when investments are made, the improvement in detection relaxes the incentive compatibility constraint, and thus enables the government to tax more the rich. These changes in taxes imply that $\widehat{\tau}_{r}=94$ percent $>\widehat{\tau}_{p}=86$ percent, and thus $I P=$ 0.176. As conjectured by Bird and Zolt (2008), the tax structure becomes progressive when investments in tax administration's technology are made. Despite this fact, which calls for a high examination coverage, the government leaves up full auditing and sets $\widehat{\pi}_{p}=0.89$. One could have expected such a result. However, its intuition must not be based on the simple assertion that investments in detection and audits are substitute ceteris paribus. In fact, we already know from Proposition 1 that, when changes in the optimal tax schedule are taken into account, the optimal frequency of audit may increase with $\delta$. Here, the optimal audit frequency decreases because the impact of the technological improvement in detection counters the increase in the rich's stake for evasion, a consequence of the improvement in the tax system's progressivity. Finally, $\widehat{g}$ increases 14.06 percent, to attain $\$ 30.58$. The new optimal investment cum fiscal policy increases the efficiency of the public sector only by 2.4 percent, whereas the expected welfare increases relatively more, by 8.7 percent.

\subsection{Comparative statics}

The next paragraphs explain in detail, with reference to the corresponding figures, how changes in one parameter affect the endogenous variables of the model. Each parameter varies within the intervals that appear in Table 1. In the figures, solid curves are obtained when investment to improve the tax administration's detection probability is optimally chosen; dashed curves, when the government is not allowed to invest. 


\subsubsection{Utility function}

Changes in the coefficient of relative risk aversion Figure 3(c) shows that, for low values of $\sigma$, the government does not enforce the tax law, and thus it does not invest. Under regime $R^{N A}$, Figures $3(\mathrm{~d})$ and (e) depict the optimal taxes. On the one hand, as the utility function becomes more concave with $\sigma$, the marginal utility of private consumption of rich evaders decreases. But this decrease is countered by the huge increase in the marginal utility of private consumption of poor. Therefore, from the second expression in (5), one can see that the optimal tax $\widehat{t}_{p}$ should decrease with $\sigma$. On the other hand, the optimal $\operatorname{tax} \widehat{t}_{r}$ is independent of $\sigma$ : from the first expression in (5) and the use of the CRRA specification for the utility function, the value of the optimal tax is completely defined by the difference $y_{r}-t_{r}$. Then, when $\sigma=0.39$, the government starts to enforce the tax law. Therefore, investing in detection becomes worthy: $\widehat{\kappa}$ jumps to 0.09 , making the detection probability to jump upwardly as well, from $\delta_{\iota}$ to 0.62 . As the audit cost is relatively low, regime $R^{F A}$ emerges immediately.
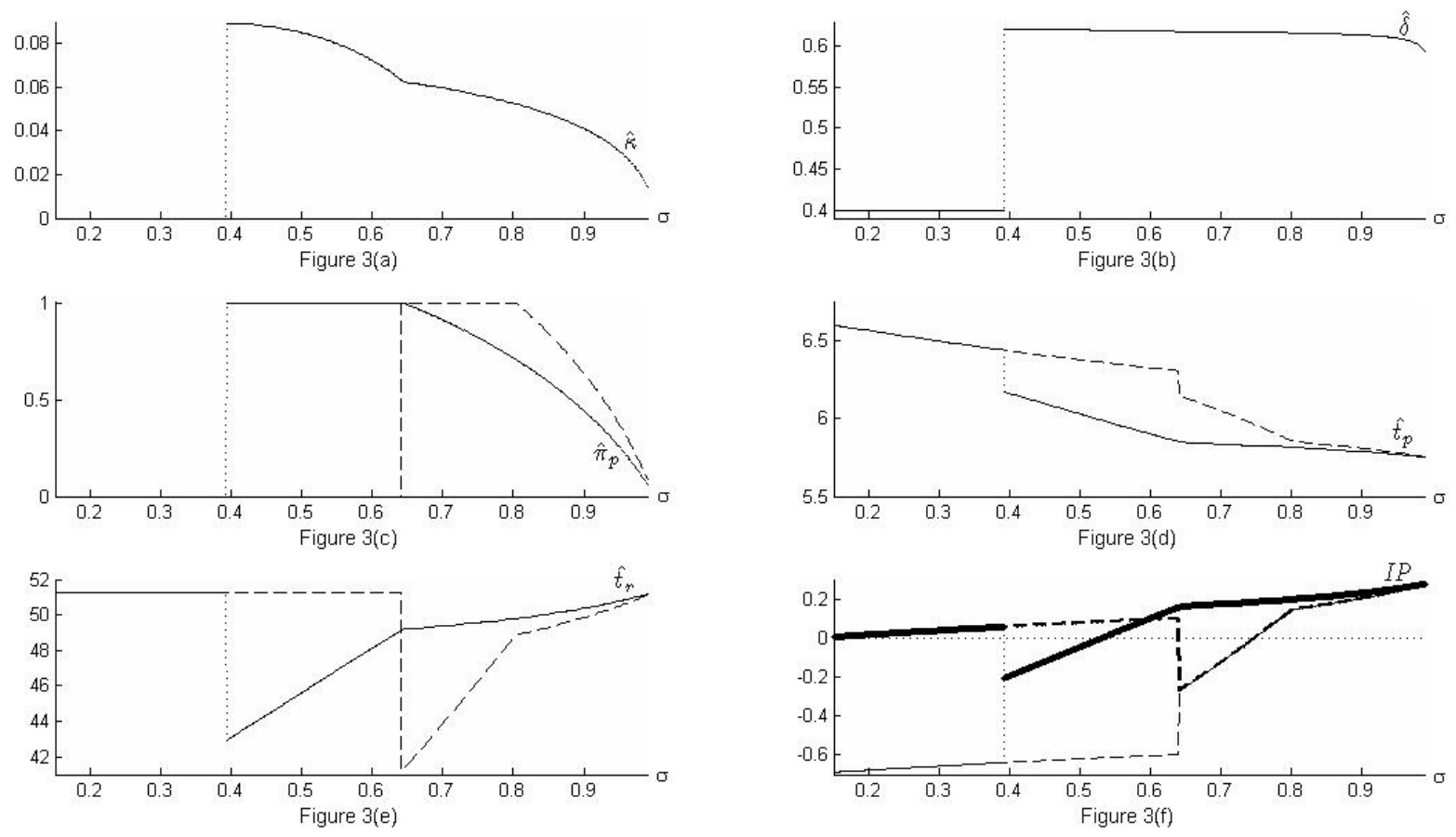

Then, when $\sigma=0.65$, the government gives up full auditing, and the other audit regime emerges, as shown in Figure 3(c). Under regime $R^{A}$, the optimal audit probability decreases with $\sigma$. Figure 3(a) shows that under both audit regimes, the optimal investment decreases and its profile is concave in $\sigma$. But when audits become random, the $\widehat{\kappa}$ 's rate of decrease jumps, and thus the $\widehat{\kappa}$ 's curve is non-differentiable at this point. The detection probability $\widehat{\delta}$ follows the variations in $\widehat{\kappa}$, albeit more attenuated: since the emergence of the audit regimes, $\widehat{\kappa}$ decreases 84.3 percent, whereas $\widehat{\delta}$ decreases only 4.31 percent. Despite the decrease in 
the detection probability, the optimal tax $\widehat{t_{p}}$ decreases, whereas the other tax $\widehat{t_{r}}$ increases. These changes affect the progressivity of the tax structure, as Figure 3(f) shows. Under regime $R^{N A}$, the tax structure is legally progressive but effectively regressive. When the full audit regime emerges, the regressiveness decreases with $\sigma$, but the tax structure cannot immediately become progressive. Only when $\sigma=0.53$, the tax structure turns out to be progressive, and its progressivity increases with this parameter. Figure $3(\mathrm{~g})$ depicts the optimal provision of public good $\widehat{g}$ : under regime $R^{N A} \widehat{g}$ decreases 0.37 percent, following the decrease in the optimal tax $\widehat{t}_{p}$; then, when $\sigma=0.39, \widehat{g}$ jumps slightly, to reach 25.8. Finally, under both audit regimes, $\widehat{g}$ increases monotonically. Figure $3(\mathrm{~h})$ shows that the EPS follows the optimal provision of public good $\widehat{g}$ : first, it decreases slightly, then it jumps upwards and starts to increase. All these changes imply that the expected welfare is non monotonic in $\sigma$, as Figure 3(i) depicts. This results is different from the rest of the simulations, where the expected welfare is monotonic in the corresponding parameter.
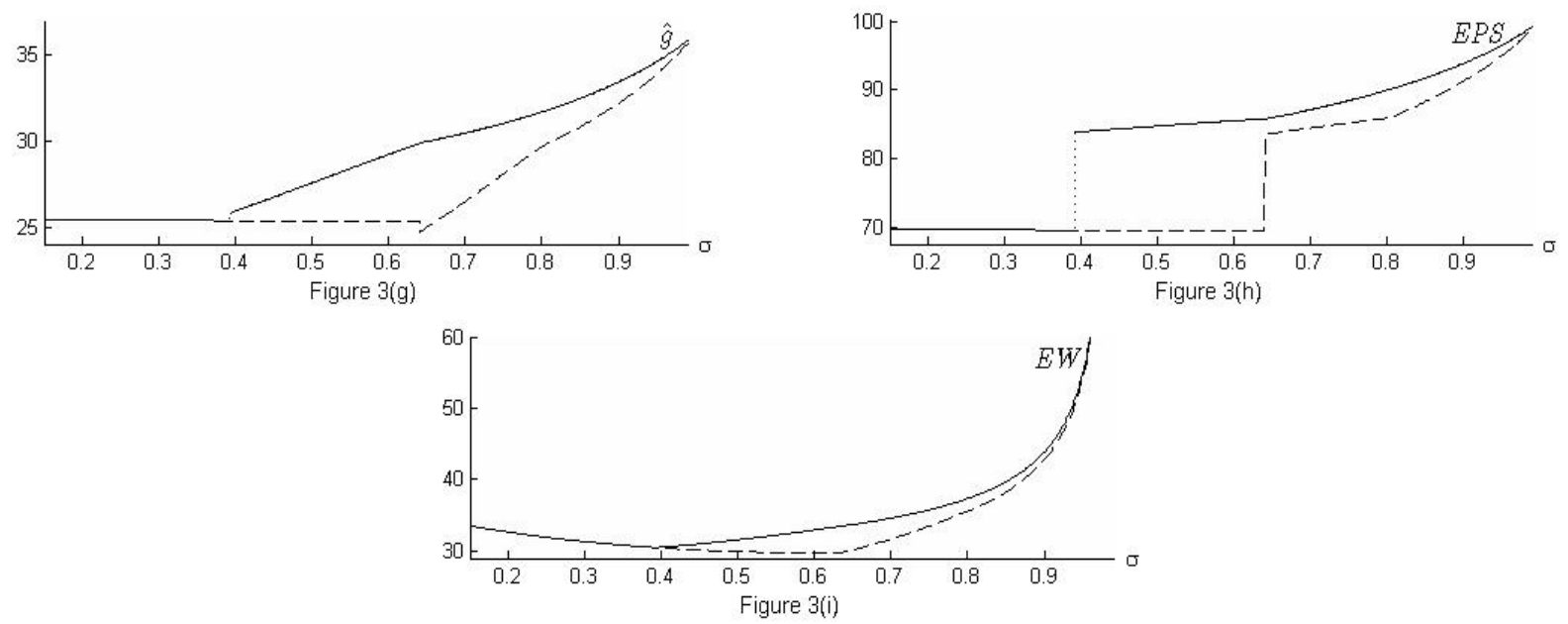

\subsubsection{Income distribution}

Changes in the proportion of rich individuals When the proportion of rich individuals $\mu \leq 0.49, \underline{\delta} \geq 0.48$, which is higher than $\delta_{\iota}=0.4$. Given the other baseline parameters, the investment that would be necessary to make $\delta>\underline{\delta}$ is, relative to the aggregate audit cost, prohibitive; so $\widehat{\kappa}=0$. As a consequence, it does not pay to enforce the tax law and thus regime $R^{N A}$ emerges. When $\mu=0.49, \widehat{\kappa}$ jumps upward to $\$ 0.067$ As $\widehat{\pi}_{p}$ also jumps upward to 0.74 , regime $R^{N A}$ shifts towards regime $R^{A}$. From $\mu=0.49$ onwards, $\widehat{\kappa}$ decreases with $\mu$, to reach 0.045 when $\mu=0.83$. When $\mu$ reaches this value, regime $R^{F A}$ emerges. Under this regime, $\widehat{\kappa}$ increases with $\mu$, attaining $\$ 0.047$ when this parameter converges to unity. Therefore, Figure 4(a) confirms that the optimal investment $\widehat{\kappa}$ can be non monotonic with respect to $\mu$, one of the ambiguous comparative static results mentioned in footnote 24. The detection probability $\widehat{\delta}$ follows $\widehat{\kappa}$ : first, it jumps upward, from $\delta_{\iota}=0,4$ to 0.62 ; then, it decreases 0.58 percent to reach 0.61 when $\mu=0.83$. Last, $\widehat{\delta}$ increases 0.98 percent, 
to reach 0.615 when $\mu$ converges to 1 . These changes in $\widehat{\delta}$ are quantitatively smaller than the variations in $\widehat{\kappa}$ because, as soon as the government does invest, the optimal detection probability adopts values that lie on the (almost) horizontal part of the curve depicted in Figure 2. Figure 4(c) shows that the optimal audit probability $\widehat{\pi}_{p}$ weakly increases: after its jump, $\widehat{\pi}_{p}$ increases monotonically, to reach unity when $\mu=0.83$. Then, regime $R^{F A}$ remains. From Figures $4(\mathrm{a})$ and (c), one may conclude that investment and audits vary with $\mu$ in opposite directions. But this assertion can be misleading: one has to compare investments with the aggregate frequency of audit $(A F A)$, which amounts to $(1-\mu) \widehat{\pi}_{p}$. Here, as $\mu$ increases, changes in the $A F A$ differ from those in $\widehat{\pi}_{p}$, as we can observe in Figure $4(\mathrm{~d})$. Under both audit regimes, the higher the fraction of rich in the population, the smaller the number of reports $\widetilde{y}_{p}$ to audit. This last effect outweighs the increase in $\widehat{\pi}_{p}$, and thus $A F A$ decreases with $\mu$. So investments and audits react in a similar way to changes in $\mu$. Figures $4(\mathrm{e})$ and (f) depict the optimal taxes. Under regime $R^{N A}, \widehat{t}_{p}$ increases with $\mu$ whereas $\widehat{t}_{r}$ remains constant, making the effective regressiveness of the tax structure to increase, as we can observe in Figure $4(\mathrm{~g})$.
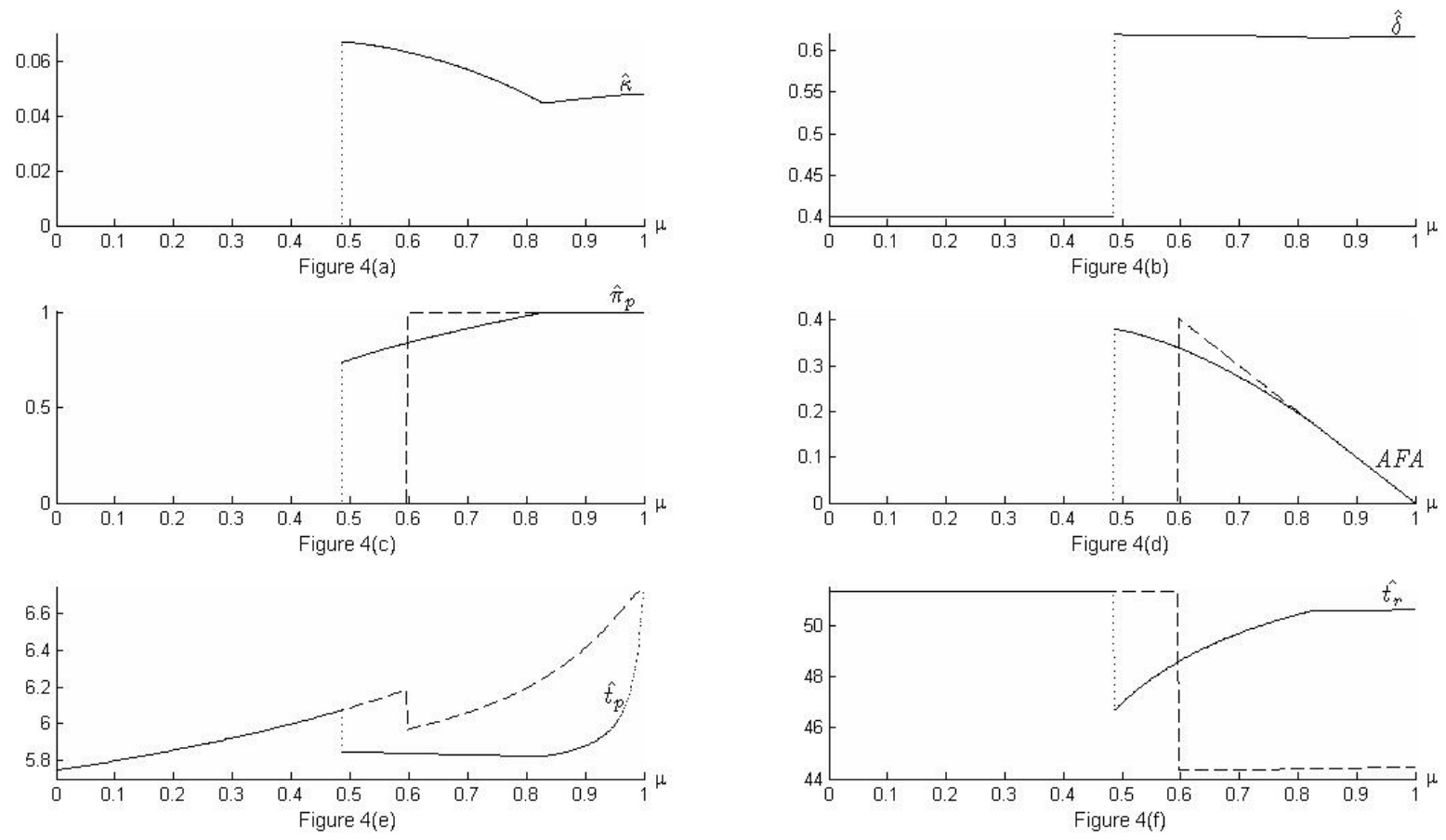

Then, when regime $R^{A}$ emerges, both taxes jump downward, from $\$ 6.07$ to $\$ 5.85$, and from $\$ 51.3$ to $\$ 46.7$, respectively. This causes the tax structure to become progressive. Under this regime, when $\mu$ increases, $\widehat{t}_{p}$ decreases 0.48 percent and $\widehat{t}_{r}$ increases 8.31 percent. These changes increase the tax structure's progressivity. But this pattern is not robust to the shift between the random and the deterministic full auditing regime. When regime $R^{F A}$ emerges, both $\widehat{t}_{p}$ and $\widehat{t}_{r}$ increase with $\mu$. But, as the former increases more in relative terms than the latter, the progressiveness of the tax structure declines. Intuitively, as $\mu$ increases, it is optimal to tax more the poor because the weight of their social marginal desutility becomes 
negligible. In particular, when $\mu \geq 0.99$, the tax structure becomes regressive. Figure $4(\mathrm{~h})$ shows that the optimal provision of public good monotonically increases, from 5.78 to 50.51 . Finally, Figure 4(i) depicts the EPS. Under regime $R^{N A}, E P S$ monotonically decreases. The reason is simple: because the number of rich that conceal their income increases faster than the tax they evade, the public good's provision increases less than the potential tax collection. Then, when the random auditing regime emerges, the EPS jumps upward, from 71 to 77.8 percent. This is due by an downward jump in the potential tax collection. After that, when $\mu$ increases the $E P S$ monotonically increases. Such increase is explained by the decrease of the aggregate audit cost.
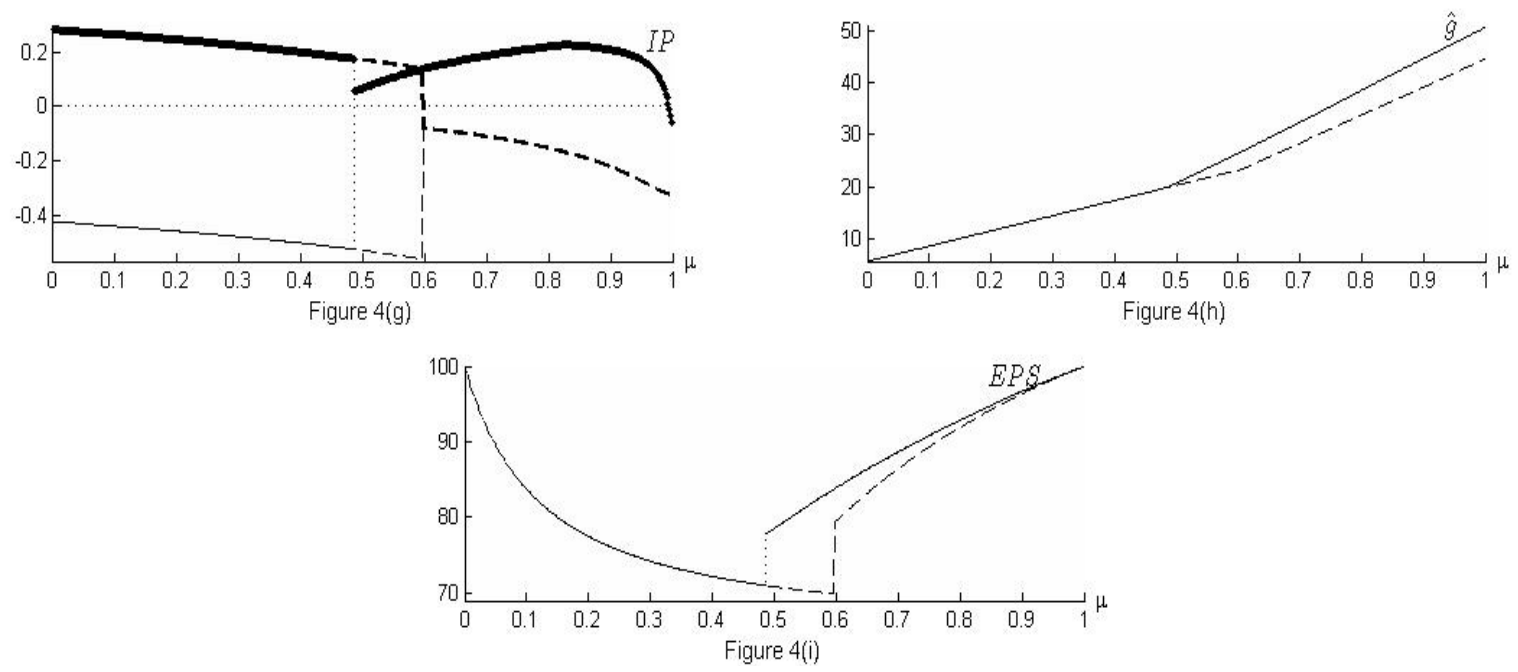

Changes in the high income When the rich's income $y_{r}<\$ 28.35, \underline{\delta}>0.61$, which is higher than $\delta_{\iota}=0.4$. Again, given the other baseline parameters, the investment that would be necessary to make $\delta>\underline{\delta}$ is, relative to the aggregate audit cost, prohibitive; so $\widehat{\kappa}=0$. As a consequence, it does not pay to enforce the tax law and thus regime $R^{N A}$ emerges. When $y_{r}=\$ 28.35, \widehat{\kappa}$ jumps upward to $\$ 0.05$. As $\widehat{\pi}_{p}$ also jumps upward to 0.68 , regime $R^{N A}$ shifts towards regime $R^{A}$. From $y_{r}=\$ 28.35$ onwards, $\widehat{\kappa}$ increases with this parameter, to reach $\$ 0.062$ when $y_{r}=\$ 78.55$. Then, regime $R^{F A}$ emerges. Under the deterministic full auditing regime, $\widehat{\kappa}$ increases further, attaining $\$ 0.077$ when $y_{r}$ converges to $\$ 100$. The detection probability $\widehat{\delta}$ follows the optimal investment $\widehat{\kappa}$ : first, it jumps upward, from $\delta_{\iota}=0,4$ to 0.616 , then it increases (only) 0.52 percent, to reach 0.619 . The reason why the changes in $\widehat{\delta}$ are quantitatively negligible is the same as explained above. Figure 5 (c) shows that the optimal audit probability $\widehat{\pi}_{p}$ weakly increases: after its jump, $\widehat{\pi}_{p}$ increases monotonically, to reach unity when $y_{r}=\$ 78.55$. Then, regime $R^{F A}$ remains. From Figures 5 (a) and 5(c), one can observe that investment and audits vary in the same direction. Figures $5(\mathrm{~d})$ and $5(\mathrm{e})$ depict the optimal taxes. Under regime $R^{N A}, \widehat{t}_{p}$ increases with $y_{r}$, at a decreasing rate; whereas $\widehat{t}_{r}$ also increases but almost linearly. Therefore, under regime $R^{N A}$, the tax structure is not only effectively regressive (as in all simulations where such 
regime emerges) but, more importantly, it is also legally regressive when $y_{r} \leq \$ 12.55$, as we can observe in Figure 5(f). Then, when regime $R^{A}$ emerges, both taxes jump downward: $\widehat{t}_{p}$, from $\$ 6.26$ to $\$ 5.96$, and $\widehat{t}_{r}$, from $\$ 27.15$ to $\$ 24.92$. These jumps cause the tax structure to become progressive. Under both audit regimes, when $y_{r}$ increases, $\widehat{t}_{r}$ increases (almost linearly) from $\$ 24.92$ to $\$ 96.58$, a 287 percent. But the other tax has not such a definite pattern: when $\$ 28.35 \leq y_{r} \leq \$ 78.55$ and random audits prevail, $\widehat{t}_{p}$ decreases 2.7 percent, to reach $\$ 5.79$, and then when $y_{r}>\$ 78.55$ and the deterministic full auditing regime emerges, it slightly increases, up to $\$ 5.80$. These differences imply that, under the audit regimes, although the tax structure is always progressive, its progressivity is non-monotonic: first, the progressivity increases; then, for higher incomes above $\$ 78.55$, it decreases. The reasons behind these tax changes are the following. When $y_{r}$ increases, the rich's stake for evasion decreases, pushing downward the need to audit reports $\widetilde{y}_{p}$. At the same time, the base for $t_{r}$ increases and the rich's marginal utility decreases, which enables the government to tax more rich taxpayers, and thus to provide more public goods. But this pushes $\pi_{p}$ upwards. Finally, and despite a small increase in $\widehat{\delta}$, the latter considerations prevail, and thus $\widehat{\pi}_{p}$ increases. When it reaches unity, and as $y_{r}$ increases, the government pursues the increase in rich's taxation. By incentive-compatibility, the tax $t_{p}$ has to increase.
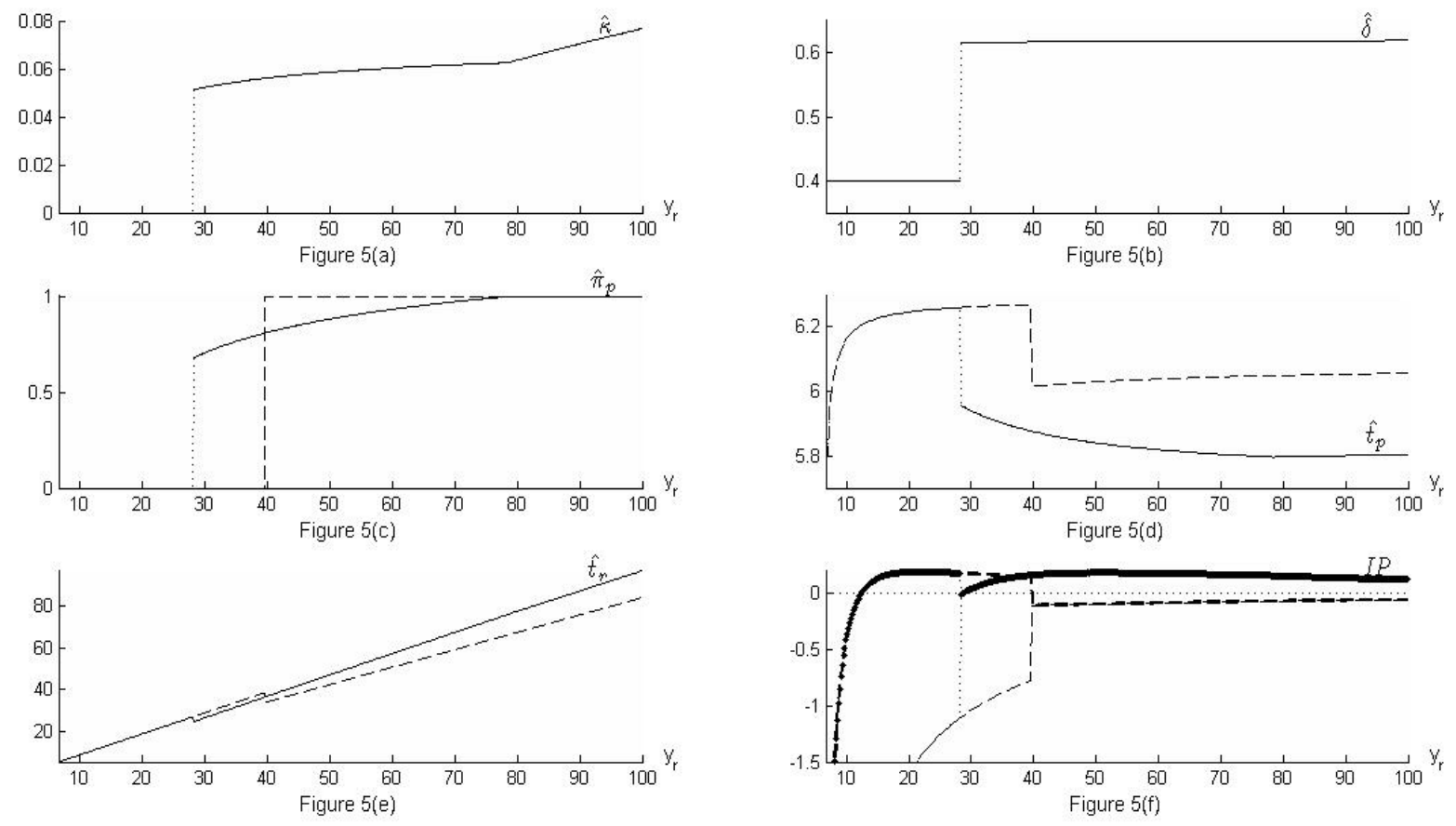

Figure $5(\mathrm{~g})$ shows that the optimal provision of public good monotonically increases, from 5.75 to 61.65 . Finally, Figure $5(\mathrm{~h})$ depicts the EPS. Under regime $R^{N A}$, the evaded tax increases with $y_{r}$. Thus the public good's provision increases less than the potential tax collection. So the EPS monotonically decreases. Then, when the audit regime emerges, the EPS jumps upward from 74.44 to 81.85 percent. After that, the EPS monotonically 
increases with $y_{r}$ but at a decreasing rate, since the aggregate audit cost is constant.
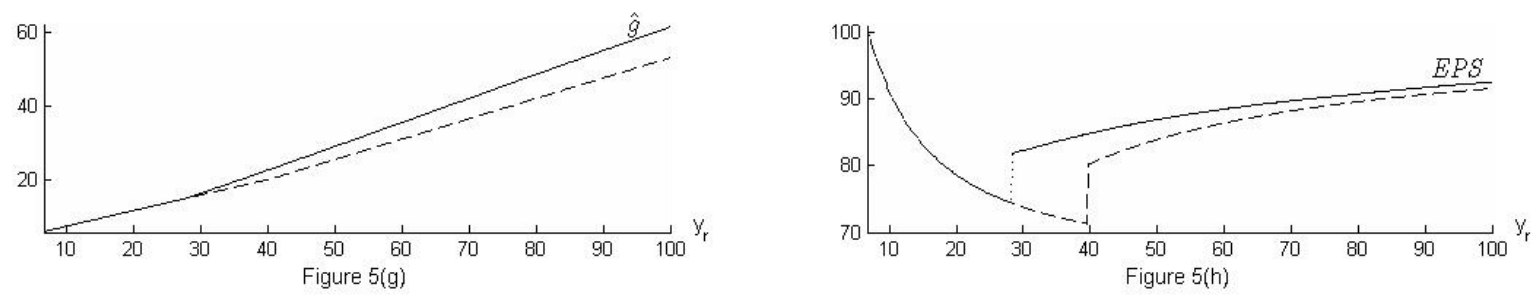

Changes in the low income When $y_{p}$ is relatively low, below $\$ 30.85$, regime $R^{A}$ emerges. Given the retained baseline parameters, the government invests to improve the tax administration's detection technology. The optimal investment $\widehat{\kappa}$ decreases with $y_{p}$ 14.64 percent. This makes the detection probability $\widehat{\delta}$ to decrease as well, but very slowly, less than 0.23 percent. The increase in the poor's income pushes the government to tax them more, as Figure 6(c) shows. Figure 6(d) depicts a different pattern: the other tax decreases slightly with $y_{p}$. Figure $6(\mathrm{e})$ shows that the tax structure is progressive when $y_{p} \leq \$ 15.35$; then onwards taxation becomes increasingly regressive, even under the audit regime. These changes in the tax structure counter the decrease in $\widehat{\delta}$, and thus the optimal audit probability also decreases with $y_{p}$. When $y_{p}=\$ 30.85$, the government gives up enforcing the tax law, thus regime $R^{N A}$ emerges, making investment worthless.
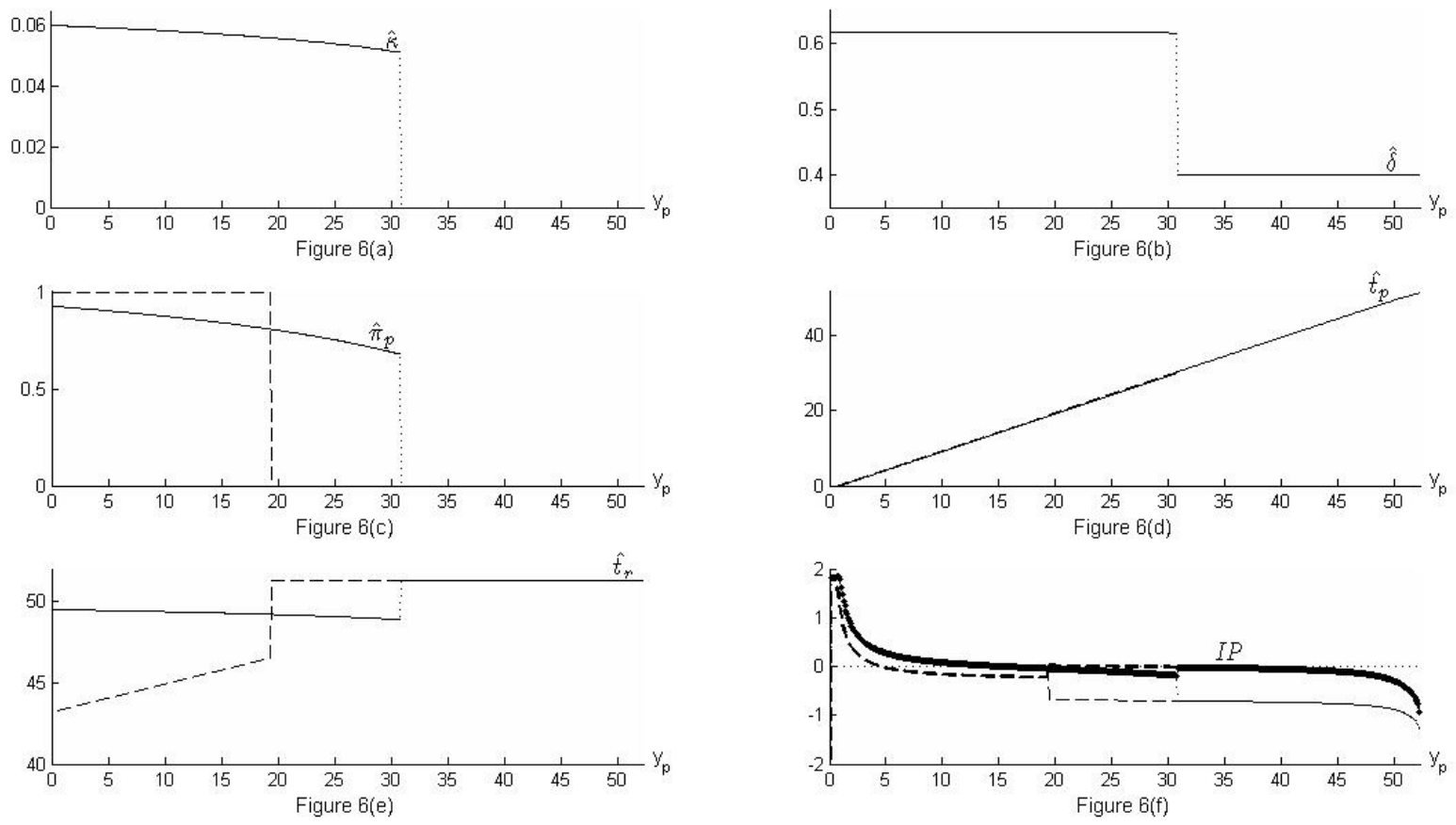
Under the no-audit regime, the optimal tax $\widehat{t}_{r}$ is independent of $y_{p}$. Obviously this is not the case of the other tax, which as expected, increases almost linearly. Surprisingly, the tax structure is not only effectively but also legally regressive there. Figure $6(\mathrm{~g})$ shows that the provision of public good monotonically increases with $y_{p}$. Finally, Figure $6(\mathrm{~h})$ depicts the behavior of the EPS. Interestingly, under both regimes the EPS increases monotonically. But, when regime $R^{A}$ shifts towards regime $R^{N A}$, the EPS jumps downward. This jump is the consequence of the upward jump in the potential tax collection and a constant public good's provision. Why the public good's provision remains constant when regimes shift? This is due to two countervailing effects: the decrease in the aggregate audit cost and the increase in the evaded tax.
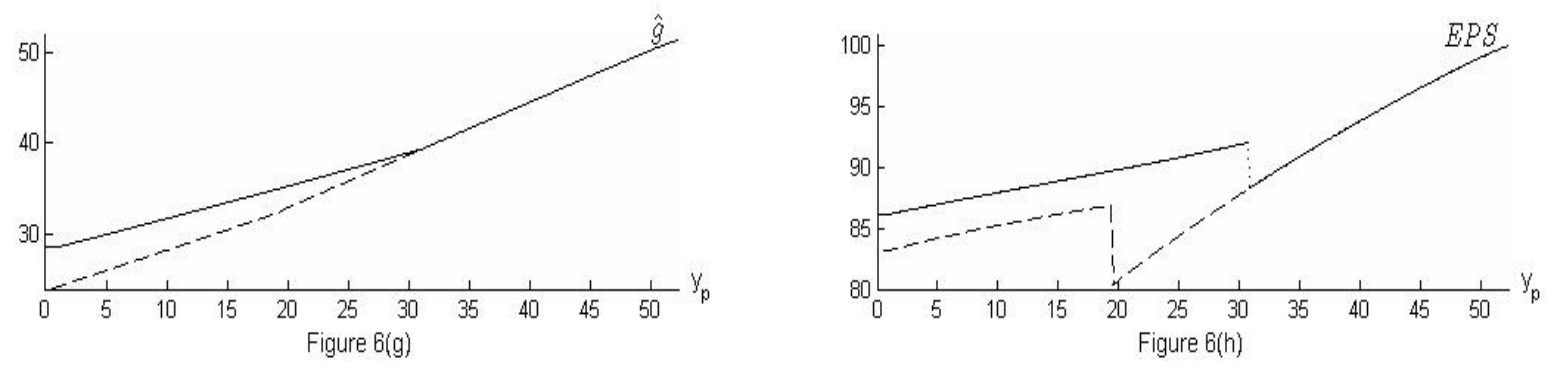

\subsubsection{Audit process}

Changes in the audit cost Figure 7(c) confirms the conjecture that one can have a priori about the pattern of emergence of the different audit regimes and its relation with the value of the audit $\operatorname{cost} c$. For a wide range of values of $c$, the tax law is effectively enforced: first, when $c \leq \$ 6.42$, all income reports $\widetilde{y}_{p}$ are audited; then, when $\$ 6.42 \leq c \leq \$ 31.98$, audits are random. Finally, when the audit cost becomes high enough, the government gives up enforcement. Figure 7 (a) shows that when $c \leq \$ 6.42$, the optimal investment $\widehat{\kappa}=\$ 0.04$. Then, under the random auditing regime $R^{A}$, when $c$ increases $\widehat{\kappa}$ also increases monotonically, to reach $\$ 0.079$. Then, $\widehat{\kappa}$ vanishes. The figure depicts one of the analytic results of the previous sections: under regime $R^{F A}$, the optimal investment $\widehat{\kappa}$ does not depend upon $c$. The reason is the following. From (8), one can see that $\widehat{\kappa}$ does not depend directly upon $c$; if it does so, it is indirectly, through the optimal taxes. But, looking at (4), optimal taxes $t_{p}^{F A}, t_{r}^{F A}$ do not depend either upon $c$. Figure $7(\mathrm{~b})$ shows that, under regime $R^{A}$, the detection probability $\widehat{\delta}$ weakly increases with $c$, from 0.613 to 0.619 , a negligible 0.96 percent. Then $\widehat{\delta}$ jumps downward, to $\delta_{\iota}$. Comparing Figures $7(\mathrm{a}), 7(\mathrm{c})$ and $7(\mathrm{~d})$, we can make the following observations. When $\widehat{\kappa}$ increases, $\widehat{\pi}_{p}$ decreases, to attain 0.74 just before the no audit regime emerges: investments and individual audits are, as expected, substitutes. But, despite the decrease in the individual frequency of audit, Figure $7(\mathrm{~d})$ shows that the aggregate audit cost $A A C$ increases, from $\$ 2.12$ to $\$ 7.76$. Hence, 
expenditures in investment and enforcement vary in the same direction.
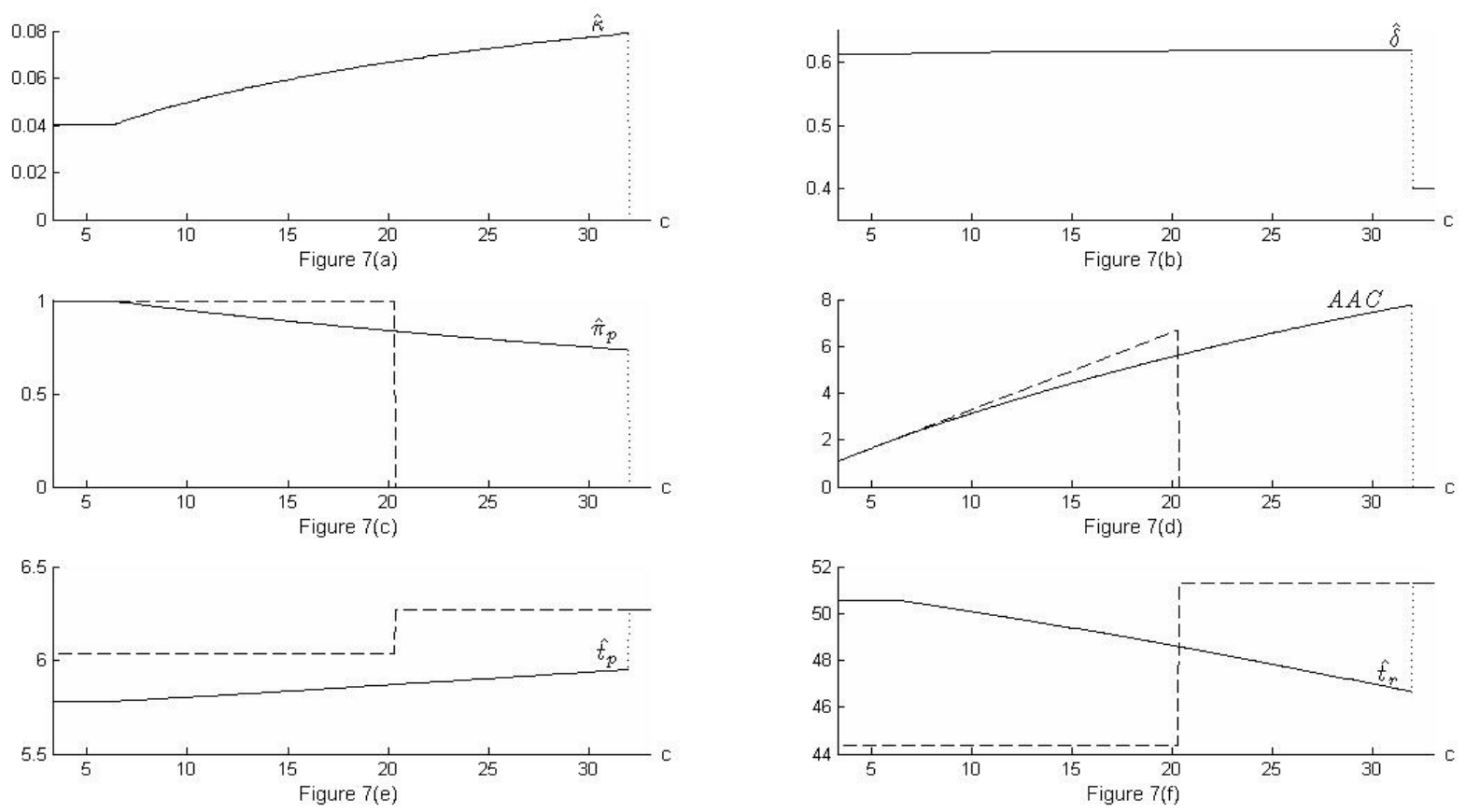

Figures $7(\mathrm{e})$ and $7(\mathrm{f})$ depict the optimal taxes. As mentioned above, both taxes are independent of $c$ under regime $R^{F A}$. But this is not the case under the other audit regime: $\widehat{t}_{p}$ $\left(\hat{t}_{r}\right)$ monotonically increases (decreases) with $c$, to reach $\$ 5.95$ (\$46.65) when $c=\$ 31.98$. In order to attenuate the audit cost's increase, the tax schedule is distorted to decrease the rich's stake for evasion, and thus the audit frequency. Then, when regime $R^{N A}$ emerges, both taxes jump upwardly, to $\$ 6.27$ and $\$ 51.3$ respectively. Figure $7(\mathrm{~g}), 7(\mathrm{~h})$ and $7(\mathrm{i})$ show that taxes and audit variations affect, in a similar negative way, the main characteristics of the fiscal policy.
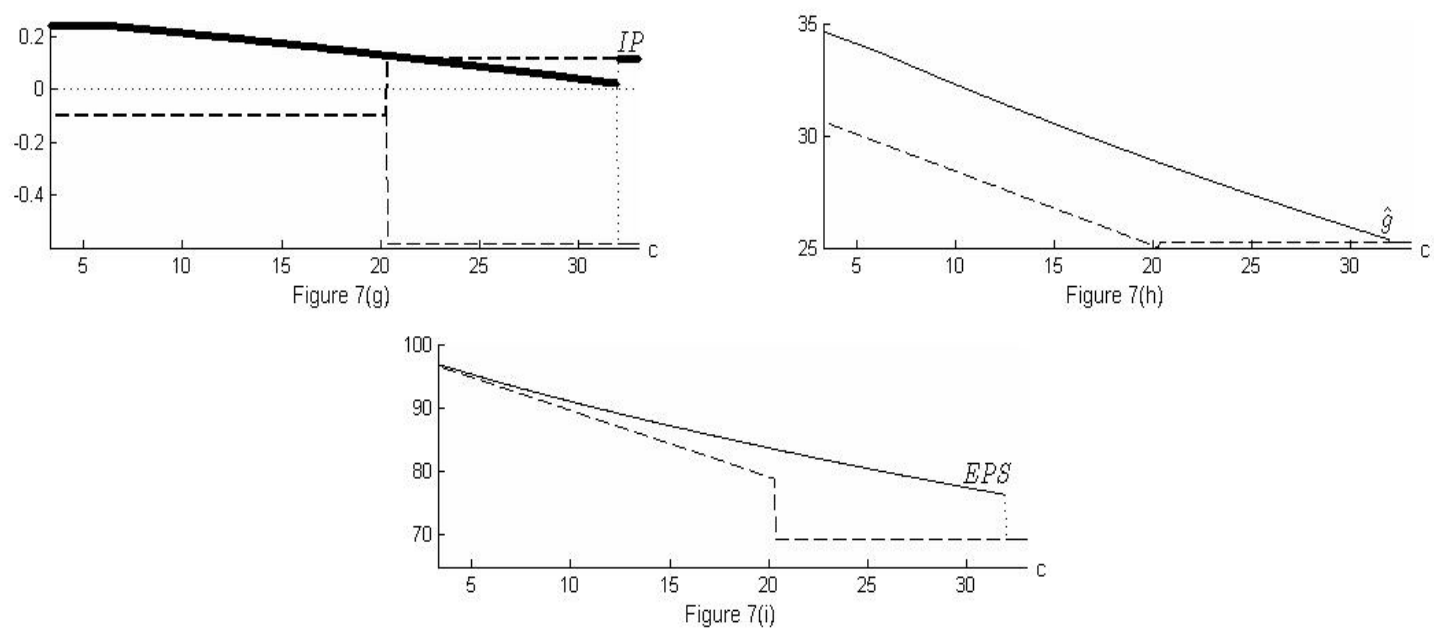
First, despite the fact that the tax system is always progressive under the audit regimes, the progressivity diminishes with $c$ under regime $R^{A}$. Similarly, both the provision of the public good and the efficiency of the public sector decrease monotonically with $c$. Investments in detection technology are not sufficient to counter the increase in the audit cost.

Changes in the initial detection probability Given our baseline parameters, the audit regimes prevail throughout this subsection. In Figure 8(a), for all possible values of the initial detection probability $\delta_{\iota}$, the government invests a strictly positive amount of resources. When $\delta_{\iota}=0.3$, the optimal investment $\widehat{\kappa}=\$ 0.07$. Then, as $\delta_{\iota}$ increases, $\widehat{\kappa}$ monotonically decreases, to reach $\$ 0.05$ when $\delta_{\iota}=0.5$. Despite the decrease in $\widehat{\kappa}$, the increase in $\delta_{\iota}$ pushes the detection probability $\delta$ to increase monotonically 38 percent from 0.52 to 0.72 , as shown in Figure 8(b). When $\delta_{\iota} \leq 0.32$, all income reports $\widetilde{y}_{p}$ are audited, thus regime $R^{F A}$ obtains; otherwise regime $R^{A}$ emerges. Under this last regime, the increase in $\delta_{\iota}$ pushes the optimal audit probability $\widehat{\pi}_{p}$ downward, to attain 0.8 when $\delta_{\iota}=0.5$. Figure $8(\mathrm{~d})$ shows that the optimal tax $\widehat{t}_{p}$ monotonically decreases with $\delta_{\iota}$, albeit slowly: from $\$ 5.87$ to $\$ 5.82$, less than 0.89 percent. Similarly, Figure $8(\mathrm{e})$ depicts the optimal tax $\widehat{t}_{r}$ : it monotonically increases from $\$ 48.6$ to $\$ 49.7$, less than 2.3 percent. Figure $8(\mathrm{f})$ illustrates the progressivity of tax structure, which increases with $\delta_{\iota}$.
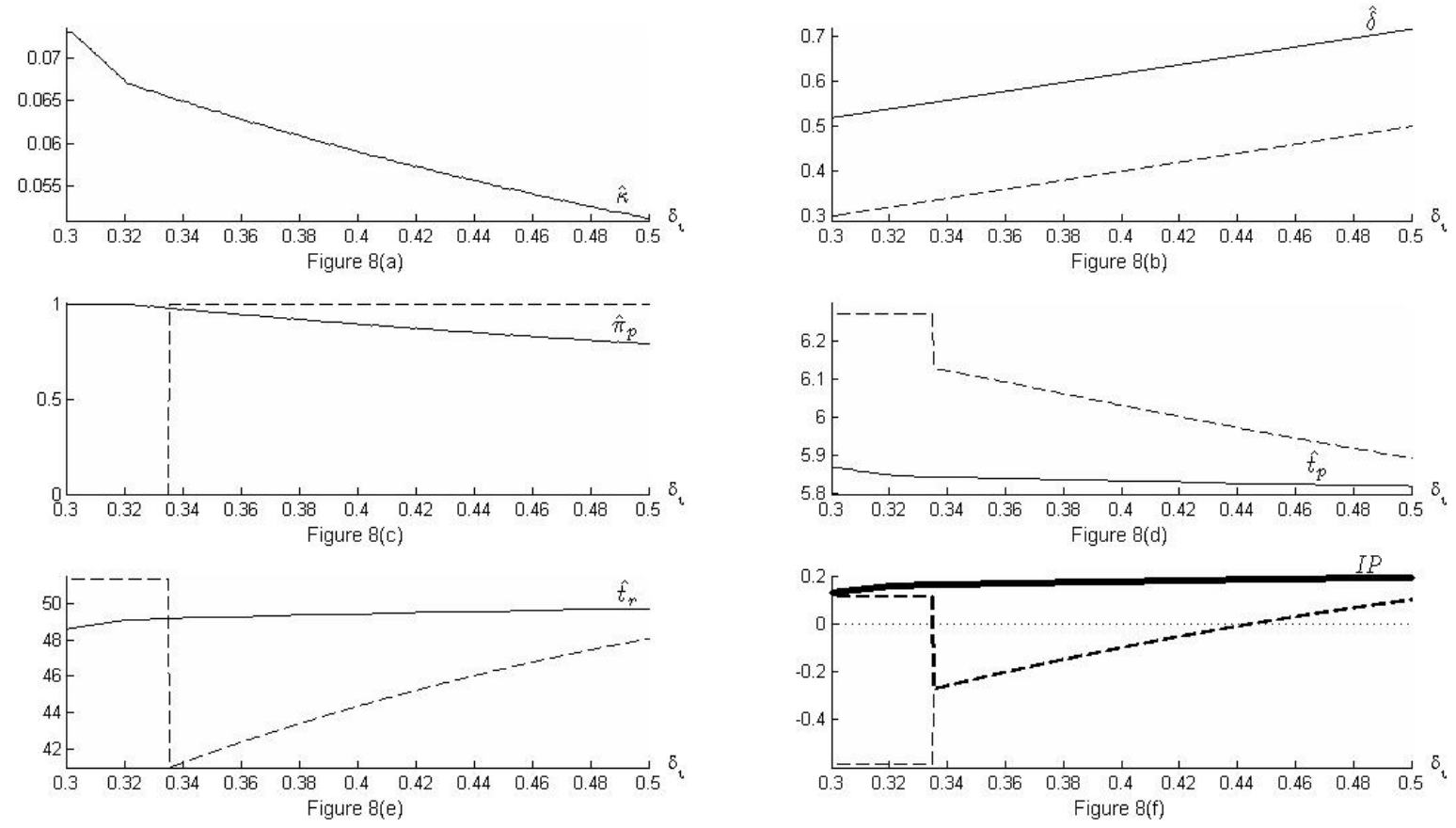

Figure $8(\mathrm{~g})$ presents the increase in the provision of the public good $\widehat{g}$, from 29.5 to 31.3 , a 6 percent increase. Finally, Figure 3(h) illustrates the efficiency of the public sector EPS, which is always higher than 85 percent, and thus increases only from 85.6 to 88.9 percent, a 3.8 percent increase for the entire domain. 

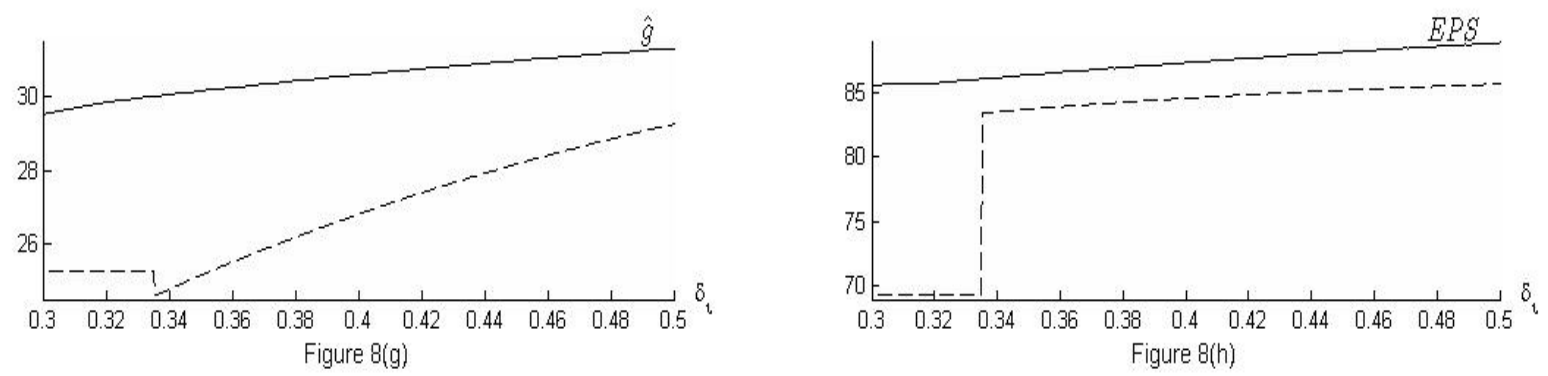

Changes in the investment productivity When $\nu=0, \widehat{\kappa}=0:$ as investments are unproductive, the government does not expend resources on them. Therefore, the model yields the same results as when investment is not an option. Moreover, the numerical simulations also show that $\widehat{\kappa}$ is a continuous function of $\nu$ when $\nu=0$. Thus, as soon as $\nu>0$, the government starts investing. Given our baseline parameters, the audit regimes prevail throughout this subsection. First, regime $R^{F A}$ emerges when $\nu \leq 0.157$. Under the deterministic full auditing regime, the optimal investment $\widehat{\kappa}$ is non monotonic: first, it increases to reach a maximum at $\widehat{\kappa}=\$ 0.054$ when $\nu=0.125$; then, it decreases, to attain $\widehat{\kappa}=\$ 0.052$ when $\nu=0.157$. Next, as the investment productivity is relatively high (and also the detection probability, as explained below), regime $R^{A}$ emerges. Under the random audit regime, the optimal investment is again non monotonic in $\nu$ : first, it increases, albeit very slowly, to reach 0.06 when $\nu=0.47$. Then, although it is imperceptible in the figure, the numerical simulations show that $\widehat{\kappa}$ monotonically decreases. What explains these inverse U-shaped relations between $\nu$ and $\widehat{\kappa}$ ? Given the retained specification, and depending upon the value of $\kappa$, the slope of the function $\delta(\kappa, \nu)$ may increase or decrease when $\nu$ increases. Therefore, the marginal benefit from an increase in $\kappa$ can be positive or negative. Despite the non-monotonicity of $\widehat{\kappa}$, the detection probability monotonically increases, from the initial level $\delta_{\iota}=0.4$ to attain 0.98 when $\nu=0.6$. Figure $9(\mathrm{c})$ shows the variations of the optimal audit probability. First, $\widehat{\pi}_{p}$ is constant; then, when $\nu$ increases above $0.157, \widehat{\pi}_{p}$ decreases, up to 0.61 when $\nu=0.6$. The optimal tax $\widehat{t}_{p}$ monotonically decreases with $\nu$, decreasing from its initial level $\$ 6.03$ to $\$ 5.84$, and then to $\$ 5.79$. The other tax $\widehat{t}_{r}$ behaves symmetrically, increasing from $\$ 44.35$ to $\$ 49.37$ under regime $R^{F A}$, and then to $\$ 50.29$ under regime $R^{A}$. Clearly, the tax variations under the deterministic 
full auditing regime are sharper than under the random auditing regime.
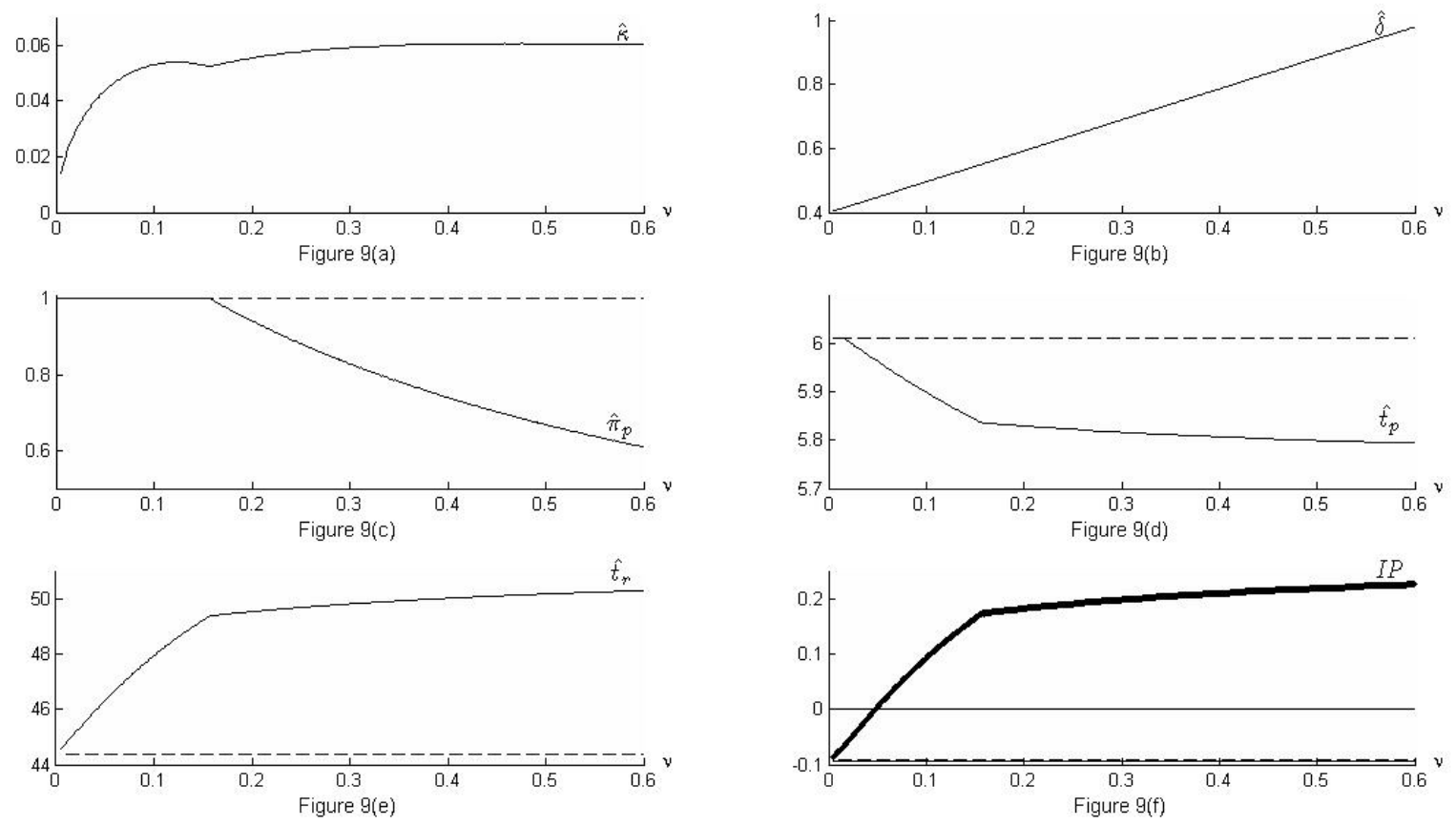

Interestingly, Figure 9(f) shows that, for relatively low values of the investment productivity, the tax structure is regressive. Indeed, when $\nu \leq 0.05$, even investing optimally in detection, the government is not able to modify the regressiveness of the tax structure that arises when it does not have such a possibility. Then, for higher values of $\nu$, the tax structure becomes increasingly progressive. Figure $9(\mathrm{~g})$ presents the increase in the provision of the public good $\widehat{g}$, from 27.37 to 32.83 , a 20 percent higher. Finally, Figure $9(\mathrm{~h})$ shows that, despite the non-monotonic variation in $\widehat{\kappa}$, the $E P S$ monotonically increases, from 86 percent to 92.20 .
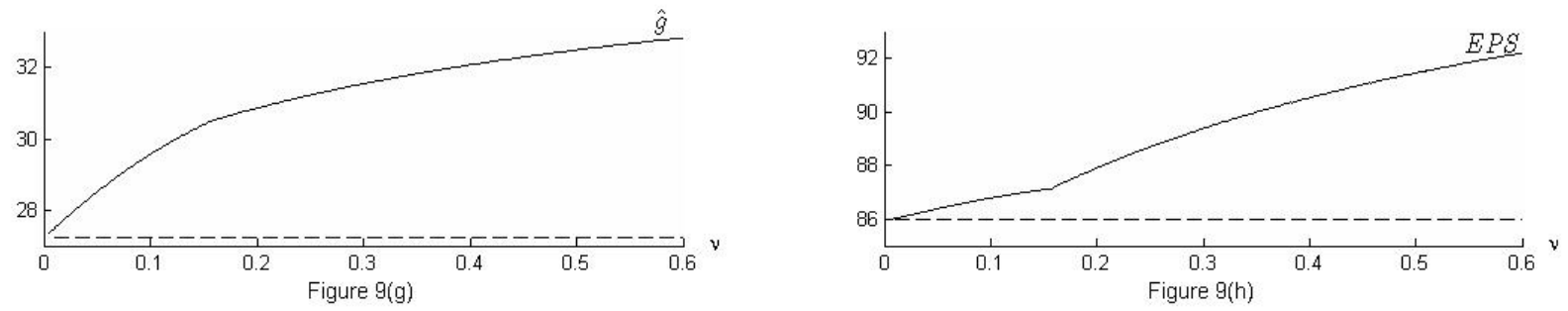

\subsection{Summary of the numerical simulations}

Here, we present the main results that emerge from the numerical simulations. Clearly, investments in detection widen the range of parameters where the tax law is enforced. 
All figures, except Figure 9(c) show that, for some parameter values of the model, one of the auditing regimes emerges with investment; whereas, if this were not an option, the government would not have enforced the tax law.

The simulations also clarify the relation between investment in detection technology and audit expenditures. The aggregate frequency of audit (or the aggregate audit cost) is sometimes higher with investment than without it simply because, as abovementioned, one of the auditing regimes can emerge, instead of regime $R^{N A}$. Under these circumstances, we can say that investment and audits are complements, since the shift from a scenario without investment to one where investment is feasible can be explained by a decrease in the price of $\kappa$, from an infinite value to one. But when one of the audit regimes prevails without investment, the optimal audit probability (or the aggregate frequency of audit) and the aggregate audit cost are always lower when the government can invest than when it cannot: investments and audits are substitutes. One could have conjectured that, as investment improves the detection probability of each individual audit, this explains such result. In fact, this reasoning is not sufficient: one has to consider the changes that investment provokes in all instruments under the government's control, in particular the tax structure. With respect to Besfamille and Parlatore Siritto (2009), this model incorporates taxation for the poor, giving to the government an additional instrument. This enables the government to definitely reduce the number of audits when it invests, a result that did not emerge in the abovementioned article.

What is less clear cut is the reaction of the optimal investment and audit probability/aggregate audit cost when some of the parameters of the model change. Interestingly, although Figures 4 and 7 show that these variables vary in opposite directions, Figures 3, 5,6 and 8 prove that they can also move similarly.

Also, the possibility of investing alters some comparative statics results of the model, in particular those pertaining to the poor's taxes. For example, in Figures 4(e) and 5(d), the tax $t_{p}$ varies with the corresponding parameter differently when the government can invest than when it cannot improve the detection technology.

Some interesting results appear when we modify the income distribution. First, the two different ways of making less equal the top of the income distribution (by increasing $\mu$ or $y_{r}$ ) have not the same impact upon the optimal level of investment under regime $R^{A}$. Figure $5(\mathrm{a})$ confirms that $\widehat{\kappa}$ increases with the rich's income, whereas Figure $4(\mathrm{a})$ shows that $\widehat{\kappa}$ decreases with the fraction of rich in the population. This difference can be explained as follows. After exogenous increases in $\mu$ or $y_{r}$, the modification of $\widehat{\kappa}$ results from the combination of two potential effects on the MSAAC in (7): i) a direct effect that occurs when the corresponding parameter change affects only $(1-\mu)$ or $\partial \pi_{p}^{A} / \partial \delta$, and ii) an indirect effect, which appears provided the parameter change modifies the values of the optimal tax schedule $\left(t_{p}^{A}, t_{r}^{A}\right)$, making the value of the derivative $\partial \pi_{p}^{A} / \partial \delta$ to vary as well. Changes in $\mu$ or $y_{r}$ cause both kind of impacts. But the direct impact of an increase in $\mu$ is linear, whereas the direct impact of an increase in $y_{r}$ is not, because it affects the privategood consumption (i.e. the argument of the utility function). Second, when each income converges to the other income's baseline level, the income distribution becomes more equal. This decreases the rich's stake for evasion and the corresponding gain from enforcement. Therefore, the government gives up enforcement and designs a regressive tax structure. 
The possibility of investment opens the door to improvements in the tax structure's progressivity. But, as some of the simulations show, under some parameter configurations of the model, investing optimally may not be sufficient to eliminate the regressiveness that characterizes the optimal tax structure when investment is not an option. This occurs when different type of parameters are considered, as the coefficient of risk aversion, the poor's income and the investment's productivity.

With the retained baseline parameters, improvements in the investment productivity generate better results, in quantitative terms, than improvements in the initial detection probability.

Finally, as a consequence of the fact that the government has most instruments to deal with tax evasion than in Besfamille and Parlatore Siritto (2009), all simulations show that the provision of the public good and the efficiency of the public sector taken as a whole increase with investment. Again, this is not evident per se because both outcomes depend upon many endogenous variables of the model.

Summing up, the simulations confirm that incorporating the endogenous improvement of the tax administration's detection technology in a model of optimal tax-enforcement policies under imperfect auditing modifies qualitatively its results, substantially in some regards.

\section{Related literature}

This paper modifies and extends the Besfamille and Parlatore Siritto (2009) model. ${ }^{33}$ On the one hand, the main difference with respect to this paper is that audits are imperfect. This complicates the analysis because the detection probability has both a direct and an indirect impact on the level of the optimal audit probability. Therefore, deterministic full auditing can be optimal, a result that was impossible in this paper. This implies that the optimal tax law is characterized either by first-order conditions (when audits are random), or by boundary conditions (under deterministic full auditing). On the other hand, we extend the abovementioned article in two dimensions. Taxing poor individuals enables us to study the impact of the initial investment upon the progressivity of the tax system. The second extension, by assuming the existence of honest taxpayers, incorporates an ethical dimension into the analysis.

To our knowledge, Boadway and Sato (2000) were the first to characterize analythically the optimal tax-enforcement policy in a setting where, after audits are performed, mistakes in assessing taxable incomes can occur. Although these authors find distortions in the optimal tax schedule that are similar to ours, there is a crucial difference between their and our framework. As their goal is to find whether 'penalizing the innocent is optimal', they

\footnotetext{
${ }^{33}$ The retained framework is similar to Mookherjee and Png (1989) and Pestieau, Possen and Slutsky (2004), which characterize optimal incentive-compatible tax-enforcement policies. But, besides the fact that these authors assume that audits are perfect and do not include investments in the tax administration, our model differs with theirs on two important aspects. First, we rule out of the model rewards for truthful reports, whereas Mookherjee and Png (1989) find that they are indeed optimal deterrents for tax evasion. Second, we include in the model the provision of public goods, whereas they follow the traditional 'optimal taxation' approach that fixes exogenously the government's revenue requirement.
} 
assume only type I errors, which is the opposite case we consider. Therefore, some of their results differ. In particular, as the payment that a poor has to make when he is audited and is erroneously identified as rich is the same as the fine that a rich has to pay when he is audited and found to have underreported his income, this payment/fine is not maximal because the government cares about the ex post welfare of innocent albeit fined poor.

We are not the first to address administrative and technological issues in optimal taxation models. Slemrod and Kopczuk (2002) analyze optimal tax systems when the government controls an administrative instrument that directly affects the elasticity of taxable income with respect to tax rates. Our model adopts a different indirect approach: investment affects utilities but only via the optimal tax law, that ultimately depends upon the level of the detection probability. Recently, Slemrod and Traxler (2009) adopt a more direct approach. As Kaplow (1998), they incorporate random observability of the tax base in the standard linear income tax problem. As the government can invest to improve the accuracy of the tax base measurement, they characterize the optimal level of investment/observability and the optimal tax schedule. The main differences with our paper are the following. First, these authors do not endogenize the public good's provision. Second, in their model, investment increases the accuracy of the tax base measurement, improvement that affects individual labor choices. In our model, the government can only determine incomes through costly imperfect audits; this affects individual's utility through another channel, namely the lower provision of the public good. Therefore, the trade-offs of the investment decision are of different nature. Regarding the tax administration's technology, Usher (1986) and Mayshar (1991) have already dealt with this item. These authors characterize the optimal amount of resources spent by governments in tax enforcement activities. To do that, they rely on reduced-form functions and assume a positive relation between these resources and the cost borne by individuals to escape from being detected (Usher)/the maximal tax collection (Mayshar). While these positive relations seem logical, our numerical results show that, when one incorporates investments that improve the tax administration's capacity to detect evaders into the model, the signs of these relations become less evident.

Finally, our model sheds new light on the question of the size and the composition of the tax administration's budget. Like many others (see Slemrod and Yitzhaki 1987, and Slemrod 1994), we take the budget of the audit section for the budget of the entire tax administration. By incorporating investment as another element of the tax administration's budget, we can show first that the relation between the audit probability and the tax administration's budget is not so direct as in Slemrod and Yitzhaki (1987). Second, we can argue about the composition of this budget, as in Wertz (1979). In particular, we can see whether investment vary in the same or in opposite direction than the aggregate audit cost.

\section{Conclusion}

There is a large list of contributions that have analyzed optimal tax-enforcement policies under the threat of tax evasion. Surprisingly, most assume that audits are perfect. Not only audits are indeed imperfect but also, in practice, governments invest many resources to 
improve the capacity of their tax administration to detect evaders. This paper is a first step towards the incorporation, in the theory of optimal fiscal policies, of these investment decisions. In a very simple model, we characterize the optimal tax-enforcement policy, adopting a mechanism design approach. As many other contributions to the costly-state verification literature, the optimal fine for evaders is maximal and the optimal audit probability is such that evasion is deterred. However, in order to attenuate the stake for evasion, the government optimally distorts taxes with respect to their full-information level. We show that deterministic full auditing can be an optimal enforcement policy. Then we analyze the optimal investment. Although we prove its existence, we cannot completely characterize the optimal investment in general.

To identify the solutions and to study how the optimal investment interacts with the other components of the optimal fiscal policy, we simulate numerically the model for parameter values representative of the US tax system and the IRS's operations in 2006. The simulations clarify the relation between investment and expenditures in audit, showing that, with investment, the aggregate audit cost may be higher than without investment. Moreover, these two endogenous variables of the model can be substitutes or complements. All simulations show that the public sector becomes more efficient with investment. Summing up, the analytic results of the model and the simulations suggest the need to incorporate the kind of investment analyzed here into the currently definitions of 'tax effort' used in empirical work.

The model can be extended in several directions. First, one can construct a similar albeit dynamic model, to include the capital's depreciation and to analyze the path of the different elements of the optimal fiscal policy. Second, our analysis can be generalized to incorporate more dimensions of heterogeneity (e.g., different degrees of risk aversion). Finally, the model generates some testable implications. All these are interesting venues for future research.

\section{References}

[1] Alm, J. (1988) Uncertain Tax Policies, Individual Behavior, and Welfare, American Economic Review 78, 237-245.

[2] Andreoni, J., B. Erard and J. Feinstein (1998) "Tax Compliance", Journal of Economic Literature 36, 818-860.

[3] Baldry, J. (1986) "Tax evasion is not a gamble: A report on two experiments", Economic Letters 22, 333-335.

[4] Beck, P. and W.-O. Jung (1989) Taxpayer compliance under uncertainty, Journal of Accounting and Public Policy 8, 1-27.

[5] Benjamini, Y. and S. Maital (1985) "Optimal tax evasion and optimal tax evasion policy", in W. Gartner and A. Wenig (eds.) The economics of the shadow economy, Springer-Verlag, Berlin. 
[6] Berge, C. (1963) Topological Spaces. New York: Macmillan.

[7] Besfamille, M. and Parlatore Siritto, C. (2009) Modernization of tax administrations and optimal fiscal policies, Journal of Public Economic Theory 11, 897-926.

[8] Bird, R. and E. Zolt (2008) Technology and Taxation in Developing Countries: From Hand to Mouse, National Tax Journal 61, 791-821.

[9] Bloch, F., and U. Zenginobuz (2006) Tiebout equilibria in local public good economies with spillovers, Journal of Public Economics 90, 1745-1763.

[10] Boadway, R. and M. Sato (2000) The Optimality of Punishing Only the Innocent: The Case of Tax Evasion 7, 641-664.

[11] Border, K., and J. Sobel (1987) Samourai Accountant: A Theory of Auditing and Plunder, Review of Economic Studies 54, 525-540.

[12] Bryan, J. (2008) Individual Income Tax returns, 2006, IRS-SOI Studies.

[13] Cebula, R. (2001) Impact of income-detection technology and other factors on aggregate income tax evasion: the case of the United States Banca Nazionale del Lavoro Quarterly Review 54, 401-415.

[14] Chander, P., and L. Wilde (1998) A General Characterization of Optimal Income Tax Enforcement, Review of Economic Studies 65, 165-183.

[15] Chetty, R. (2006) A New Method of Estimating Risk Aversion, American Economic Review 96, 1821-1834.

[16] Cowell, F. (1990) Cheating the Government. Cambridge: The MIT Press.

[17] Cremer, H., and F. Gahvari (1994) Tax Evasion, Concealment and the Optimal Linear Income Tax, Scandinavian Journal of Economics 96, 219-239.

[18] Cremer, H., and F. Gahvari (1995) Tax evasion and the optimum general income tax, Journal of Public Economics 60, 235-249.

[19] Cremer, H., M. Marchand and P. Pestieau (1990) Evading, Auditing and Taxing The Equity-Efficiency Tradeoff, Journal of Public Economics 43, 67-92.

[20] Erard, B. and J. Feinstein (2010) Econometric models for multi-stage audit processes: an application to the IRS National Research Program, in Developing Alternative Frameworks for Explaining Tax Compliance, Alm, J., Mártinez-Vazquez, J., and B. Torgler (eds). New York: Routledge Publishing.

[21] Feinstein, J.(1991) An Econometric Analysis of Income Tax Evasion and its Detection, RAND Journal of Economics 22, 14-35.

[22] General Accounting Office (1999) IRS Audits Weaknesses in Selecting and Conducting Correspondence Audits, GAO-99-48. 
[23] General Accounting Office (2008) Internal Revenue Service Review of the Fiscal Year 2010 Budget Request, GAO-09-754.

[24] Gordon, J. (1989) "Individual morality and reputation costs as deterrents to tax evasion", European Economic review, 33, 797-805.

[25] Graetz, M., J. Reinganum and L. Wilde (1986) The Tax Compliance Game: Toward an Interactive Theory of Law Enforcement, Journal of Law, Economics and Organization 2, 1-32.

[26] Herman, T. (2007) IRS plans to Revive its Random-Audit Program, The Wall Street Journal, June 24th.

[27] Hunter, W., and M. Nelson (1996) An IRS production function, National Tax Journal 49, 105-115.

[28] IRS (2006) "IRS Updates Tax Gap Estimates," IRS-2006-28.

[29] IRS (2007a) IT 'Modernization Vision \& Strategy', Publication \#49100X. Washington, DC.

[30] IRS (2007b) Data Book 2006, Publication \#55B. Washington, DC.

[31] Kaplow, L. (1990) Optimal Taxation with Costly Enforcement and Evasion, Journal of Public Economics 43, 221-236.

[32] Kaplow, L. (1998) Accuracy, Complexity, and the Income Tax, Journal of Law, Economics and Organization 14, 61-83.

[33] Kofman, F. and J. Lawarrée (1996) "On the optimality of allowing collusion", Journal of Public Economics 61, 383-407.

[34] Marhuenda, F., and I. Ortuño-Ortín (1997) Tax Enforcement Problems, Scandinavian Journal of Economics 99, 61-72.

[35] Mayshar, J. (1991) Taxation with Costly Administration, Scandinavian Journal of Economics 93, 75-88.

[36] Melumad, N., and D. Mookherjee (1989) Delegation as commitment: the case of income tax audits, RAND Journal of Economics 20, 139-163.

[37] Mookherjee, D. and I. Png (1989) Optimal Auditing, Insurance and Redistribution, The Quarterly Journal of Economics 104, 399-415.

[38] Mookherjee, D. and I. Png (1990) Enforcement Costs and the Optimal Progressivity of Income Taxes. Journal of Law, Economics, and Organizations 6, 411-431.

[39] Pestieau, P., U. Possen and S. Slutsky (1994) Optimal Differential Taxes and Penalties, Public Finance 49, 15-27. 
[40] Pestieau, P., U. Possen and S. Slutsky (2004) Jointly Optimal Taxes and Enforcement Policies in Response to Tax Evasion, Journal of Public Economic Theory 6, 337-374.

[41] Picard, P. (1996) "Auditing claims in the insurance market with fraud: The credibility issue", Journal of Public Economics 63, 27-56.

[42] Radian, A. (1980) Resource Mobilization in Poor Countries: Implementing Tax Reform. New Brunswick: Transaction Books.

[43] Ray, D., and R. Vohra (2001) Coalitional Power and Public Goods, Journal of Political Economy 109, 1355-1384.

[44] Reinganum, J. and L. Wilde (1988) A Note on Enforcement Uncertainty and Taxpayer Compliance, The Quarterly Journal of Economics 103, 793-798.

[45] Sanchez, I., and J. Sobel (1993) Hierachical design and enforcement of income tax policies, Journal of Public Economics 50, 345-369.

[46] Sandmo, A. (1981) Income Tax Evasion, Labour Supply and the Equity-Efficiency Trade-Off, Journal of Public Economics 16, 265-288.

[47] Scotchmer, S. and Slemrod, J. (1989) Randomnes In Tax Enforcement, Journal of Public Economics 38, 17-32.

[48] Silberberg, E. (1978) The Structure of Economics A Mathematical Analysis. New York: McGraw-Hill.

[49] Slemrod, J. (1990) Optimal Taxation and Optimal Tax Systems, Journal of Economic Perspectives 4, 157-178.

[50] Slemrod, J. (1994) Fixing the leak in Okun's bucket Optimal tax progressivity when avoidance can be controlled, Journal of Public Economics 55, 41-51.

[51] Slemrod, J., and W. Kopczuk (2002) The optimal elasticity of taxable income, Journal of Public Economics 84, 91-112.

[52] Slemrod, J. and C. Traxler (2009) Optimal observability in a linear income tax, WP 2010/04, Max Planck Institute for Research on Collective Goods, Bonn.

[53] Slemrod, J., and S. Yitzhaki (1987) The Optimal Size of a Tax Collection Agency, Scandinavian Journal of Economics 89, 183-192.

[54] Snavely, K. (1988) Innovations in State Tax Administrations, Public Administration Review 48, 903-910.

[55] Spicer, M. and S. Lundstedt (1976) "Understanding Tax Evasion", Public Finance 31, 295-304.

[56] Takayama, A. (1985) Mathematical Economics. Cambridge: Cambridge University Press. 
[57] Torgler, B. (2007) Tax Compliance and Tax Morale. Cheltenham/Northampton: Edward Elgar Publising.

[58] Usher, D. (1986) Tax evasion and the marginal cost of public funds, Economic Inquiry 24, 563-586.

[59] US Values Survey (2006), in http://www.knowledgenetworks.com.

[60] Vakneen, Y., and S. Yitzhaki (1989) The Shadow Price of a Tax Inspector, Public Finance 44, 492-505.

[61] Wertz, K. (1979) Allocation by and output of a tax-administering agency, National Tax Journal 32, 143-157. 


\section{Appendix}

\subsection{Characterization of the optimal tax law under random au- diting}

\section{$\underline{\text { First-order conditions }}$}

The government solves the following problem

$$
\mathcal{P}_{2}^{A} \begin{cases}\underset{t_{p}, t_{r}}{M a x} \mu u\left(y_{r}-t_{r}\right)+(1-\mu) u\left(y_{p}-t_{p}\right)+g & \\ \text { subject to } & \\ 0 \leq \pi_{p} \leq 1 & \left(L L_{p}\right) \\ t_{p} \leq y_{p} & \left(L L_{r}^{\prime}\right) \\ t_{r}+f_{r, p} \leq y_{r} & (I C) \\ u\left(y_{r}-t_{r}\right) \geq\left(1-\delta \pi_{p}\right) u\left(y_{r}-t_{p}\right)+\delta \pi_{p} u\left(y_{r}-t_{r}-f_{r, p}\right) & \left(B^{\prime}\right)\end{cases}
$$

To solve this problem, we momentarily neglect the constraints on the audit probability, and we later check them. At the optimum, $\left(L L_{r}^{\prime}\right)$ and $(I C)$ bind. Combining these binding constraints, we obtain the optimal audit probability

$$
\pi_{p}^{A}=\frac{1}{\delta}\left(1-\frac{u\left(y_{r}-t_{r}\right)}{u\left(y_{r}-t_{p}\right)}\right) .
$$

Then, we obtain $g$ from $\left(B^{\prime}\right)$. So, replacing $\pi_{p}^{A}$ and $g$ in $W$, the maximand of $\mathcal{P}_{2}^{A}$ becomes

$$
\Omega\left(t_{p}, t_{r}\right)=\mu\left[u\left(y_{r}-t_{r}\right)+t_{r}\right]+(1-\mu)\left[u\left(y_{p}-t_{p}\right)+t_{p}\right]-\frac{(1-\mu)}{P}\left(1-\frac{u\left(y_{r}-t_{r}\right)}{u\left(y_{r}-t_{p}\right)}\right) c-\kappa .
$$

The first-order conditions that characterize an interior optimal tax schedule are

$$
\left\{\begin{array}{l}
u_{q}\left(y_{p}-t_{p}^{A}\right)=1+\frac{u\left(y_{r}-t_{r}^{A}\right) u_{q}\left(y_{r}-t_{p}^{A}\right)}{\delta\left[u\left(y_{r}-t_{p}^{A}\right)\right]^{2}} c>1 \\
u_{q}\left(y_{r}-t_{r}^{A}\right)=\frac{1}{1+\frac{(1-\mu) c}{\delta \mu u\left(y_{r}-t_{p}^{A}\right)}}<1 .
\end{array}\right.
$$

By concavity of the function $u(), t_{p}^{A}>t_{p}^{*}$ and $t_{r}^{A}<t_{r}^{*}$.

\section{$\underline{\text { Second-order conditions }}$}

To verify the second-order conditions, we evaluate if the Hessian matrix

$$
H=\left[\begin{array}{ll}
\Omega_{t_{r} t_{r}} & \Omega_{t_{r} t_{p}} \\
\Omega_{t_{r} t_{p}} & \Omega_{t_{p} t_{p}}
\end{array}\right]
$$


is semi-definite negative at the optimum. Using the first-order conditions of the problem, the second derivatives of $\Omega$ are:

$$
\begin{aligned}
& \Omega_{t_{r} t_{r}}=\mu \frac{u_{q q}\left(y_{r}-t_{r}^{A}\right)}{u_{q}\left(y_{r}-t_{r}^{A}\right)}<0 \\
& \Omega_{t_{r} t_{p}}=W_{t_{p} t_{r}}=-(1-\mu) \frac{u_{q}\left(y_{r}-t_{r}^{A}\right)}{u\left(y_{r}-t_{r}^{A}\right)}\left[u_{q}\left(y_{p}-t_{p}^{A}\right)-1\right]<0 \\
& \Omega_{t_{p} t_{p}}=(1-\mu)\left\{u_{q q}\left(y_{p}-t_{p}^{A}\right)+\left[u_{q}\left(y_{p}-t_{p}^{A}\right)-1\right]\left[2 \frac{u_{q}\left(y_{r}-t_{p}^{A}\right)}{u\left(y_{r}-t_{p}^{A}\right)}-\frac{u_{q q}\left(y_{r}-t_{p}^{A}\right)}{u_{q}\left(y_{r}-t_{p}^{A}\right)}\right]\right\} \gtreqless 0
\end{aligned}
$$

Due to the general non-convexity of the problem $\mathcal{P}_{2}^{A}$, it is not possible to verify analythically the second-order conditions. Despite this fact, we will assume that $\Omega_{t_{p} t_{p}}<0$, which is a necesary condition for the second-order conditions to hold.

\section{Comparative statics}

By the Maximum theorem (see Berge 1963), the optimal taxes $t_{p}^{A}, t_{r}^{A}$ are continuous functions of the detection probability $\delta$, and so are $\pi_{p}^{A}$ and $f_{r, p}$. In order to completely characterize the optimal tax law $\left(t_{p}^{A}, t_{r}^{A}, f_{r, p}, \pi_{p}^{A}\right)$, we differentiate totally the system (11) and we apply the Implicit Function theorem. We obtain

$$
\begin{gathered}
\frac{\partial t_{p}^{A}}{\partial \delta}=\frac{1}{\Delta \delta}\left[\Omega_{t_{r} t_{r}} u\left(y_{r}-t_{r}^{A}\right) u_{q}\left(y_{r}-t_{p}^{A}\right)+\frac{u_{q}\left(y_{r}-t_{r}^{A}\right)}{u\left(y_{r}-t_{p}^{A}\right)} \Omega_{t_{r} t_{p}}\right]<0, \\
\frac{\partial t_{r}^{A}}{\partial \delta}=\frac{-1}{\Delta \delta}\left[\frac{u_{q}\left(y_{r}-t_{r}^{A}\right)}{u\left(y_{r}-t_{p}^{A}\right)} \Omega_{t_{p} t_{p}}+\Omega_{t_{r} t_{p}} u\left(y_{r}-t_{r}^{A}\right) u_{q}\left(y_{r}-t_{p}^{A}\right)\right]>0, \\
\frac{\partial \pi_{p}^{A}}{\partial \delta}=-\frac{\pi_{p}^{A}}{\delta}-\left(\frac{u_{q}\left(y_{p}-t_{p}^{A}\right)-1}{c}\right) \frac{\partial t_{p}^{A}}{\partial \delta}+\left(\frac{\mu}{1-\mu} \frac{1-u_{q}\left(y_{r}-t_{r}^{A}\right)}{c}\right) \frac{\partial t_{r}^{A}}{\partial \delta} \gtreqless 0 .
\end{gathered}
$$

where $\Delta=\Omega_{t_{r} t_{r}} \Omega_{t_{p} t_{p}}-\left(\Omega_{t_{r} t_{p}}\right)^{2}>0$.

\section{Domain of positive taxation}

Replacing $t_{p}^{A}$ and $t_{r}^{A}$ by $t_{0}$ in (11), the values of $t_{0}$ and $\delta_{0}$ can be implicitly obtained from the following system

$$
\left\{\begin{array}{l}
u_{q}\left(y_{p}-t_{0}\right)=1+\frac{u_{q}\left(y_{r}-t_{0}\right)}{\delta_{0} u\left(y_{r}-t_{0}\right)} c \\
u_{q}\left(y_{r}-t_{0}\right)=\frac{1}{1+\frac{(1-\mu) c}{\delta_{0} \mu u\left(y_{r}-t_{0}\right)}}<1 .
\end{array} .\right.
$$

Hence, when $\delta=\delta_{0}, t_{p}^{A}=t_{r}^{A}=t_{0}$; otherwise, $0<t_{p}^{A}<t_{0}<t_{r}^{A}$.

\section{Non-monotonicity of the optimal audit probability}

As shown in (12), the sign of $\partial \pi_{p}^{A} / \partial \delta$ is generally ambiguous. By a continuity argument, $\partial \pi_{p}^{A} / \partial \delta$ is positive in a neighborhood of $\delta_{0}$ because $\lim _{\delta \rightarrow \delta_{0}} \partial \pi_{p}^{A} / \partial \delta>0$. So either $\pi_{p}^{A}$ always increases with $\delta$, or we can find parameter conditions such that $\pi_{p}^{A}$ is inversely U-shaped with $\delta$. 


\title{
7.2 Characterization of the optimal tax law under deterministic full auditing
}

\author{
$\underline{\text { First-order conditions }}$
}

The government solves the following problem

$$
\mathcal{P}_{2}^{F A} \begin{cases}\operatorname{Max}_{t_{p}, t_{r}} \quad \mu\left[u\left(y_{r}-t_{r}\right)+t_{r}\right]+(1-\mu)\left[u\left(y_{p}-t_{p}\right)+t_{p}\right]-(1-\mu) c-\kappa & \\ \text { subject to } & \\ \pi_{p}^{F A}=1 & \left(L L_{p}\right) \\ t_{p} \leq y_{p} & \left(L L_{r}^{\prime \prime}\right) \\ t_{r}+f_{r, p} \leq y_{r} & \end{cases}
$$

Neglecting the two limited-liability constraints, the Lagrangean of $\mathcal{P}_{2}^{F A}$ is

$$
\mathcal{L}\left(t_{p}, t_{r}, \lambda\right)=\mu\left[u\left(y_{r}-t_{r}\right)+t_{r}\right]+(1-\mu)\left[u\left(y_{p}-t_{p}\right)+t_{p}\right]-\lambda\left[1-\delta-\frac{u\left(y_{r}-t_{r}\right)}{u\left(y_{p}-t_{p}\right)}\right]
$$

where $\lambda>0$ is the multiplier associated to the full-auditing constraint. The first-order conditions that characterize an optimal tax schedule $\left(t_{p}^{F A}, t_{r}^{F A}\right)$ are

$$
\left\{\begin{array}{l}
\mathcal{L}_{t_{p}}=(1-\mu)\left[1-u_{q}\left(y_{p}-t_{p}^{F A}\right)\right]+\lambda(1-\delta) \frac{u_{q}\left(y_{r}-t_{p}^{F A}\right)}{u\left(y_{r}-t_{p}^{F A}\right)}=0 \\
\mathcal{L}_{t_{r}}=\mu\left[1-u_{q}\left(y_{r}-t_{r}^{F A}\right)\right]-\lambda \frac{u_{q}\left(y_{r}-t_{r}^{F A}\right)}{u\left(y_{r}-t_{p}^{F A}\right)}=0 \\
\mathcal{L}_{\lambda}=1-\delta-\frac{u\left(y_{r}-t_{r}^{F A}\right)}{u\left(y_{p}-t_{p}^{F A}\right)}=0
\end{array}\right.
$$

\section{$\underline{\text { Second-order conditions }}$}

To verify the second-order conditions, we evaluate if the Bordered Hessian matrix

$$
B H=\left[\begin{array}{ccc}
\mathcal{L}_{t_{r} t_{r}} & \mathcal{L}_{t_{r} t_{p}} & \mathcal{L}_{t_{r} \lambda} \\
\mathcal{L}_{t_{r} t_{p}} & \mathcal{L}_{t_{p} t_{p}} & \mathcal{L}_{t_{p} \lambda} \\
\mathcal{L}_{t_{r} \lambda} & \mathcal{L}_{t_{p} \lambda} & 0
\end{array}\right],
$$

is semi-definite negative at the optimum. Using the first-order conditions of the problem, 
the second derivatives of the Lagrangean function $\mathcal{L}($ ) are:

$$
\begin{aligned}
& \mathcal{L}_{t_{r} t_{r}}=u_{q q}\left(y_{r}-t_{r}^{F A}\right)\left[\mu+\frac{\lambda}{u\left(y_{r}-t_{p}^{F A}\right)}\right]<0 \\
& \mathcal{L}_{t_{r} t_{p}}=-\frac{\lambda}{\left[u_{q}\left(y_{r}-t_{p}^{F A}\right)\right]^{2}} u_{q}\left(y_{r}-t_{r}^{F A}\right) u_{q}\left(y_{r}-t_{p}^{F A}\right)<0 \\
& \mathcal{L}_{t_{p} t_{p}}=(1-\mu) u_{q q}\left(y_{p}-t_{p}^{F A}\right)+\lambda(1-\delta)\left[2\left(\frac{u_{q}\left(y_{r}-t_{p}^{F A}\right)}{u\left(y_{r}-t_{p}^{F A}\right)}\right)^{2}-\frac{u_{q q}\left(y_{r}-t_{p}^{F A}\right)}{u\left(y_{r}-t_{p}^{F A}\right)}\right] \gtreqless 0 \\
& \mathcal{L}_{t_{r} \lambda}=-\frac{u_{q}\left(y_{r}-t_{r}^{F A}\right)}{u\left(y_{r}-t_{p}^{F A}\right)}<0 \\
& \mathcal{L}_{t_{p} \lambda}=(1-\delta) \frac{u_{q}\left(y_{r}-t_{p}^{F A}\right)}{u\left(y_{r}-t_{p}^{F A}\right)}>0
\end{aligned}
$$

Due to the general non-concavity of the problem $\mathcal{P}_{2}^{F A}$, it is not possible to verify analythically the sign of $\mathcal{L}_{t_{p} t_{p}}$. We assume $\mathcal{L}_{t_{p} t_{p}}<0$. If this is so, $\operatorname{det} B H>0$. Thus, the second-order conditions hold (See Silberberg 1978).

\section{Comparative statics}

In order to completely characterize the optimal tax law $\left(t_{p}^{F A}, t_{r}^{F A}\right)$, we differentiate totally the system (14) and we apply the Implicit Function theorem. We obtain

$$
\begin{aligned}
& \frac{\partial t_{p}^{F A}}{\partial \delta}=\frac{1}{\operatorname{det} B H}\left[\mathcal{L}_{t_{r} t_{r}} \mathcal{L}_{t_{p} \lambda}-\mathcal{L}_{t_{r} t_{p}} \mathcal{L}_{t_{r} \lambda}\right]<0, \\
& \frac{\partial t_{r}^{F A}}{\partial \delta}=\frac{1}{\operatorname{det} B H}\left[\mathcal{L}_{t_{r} t_{p}} \mathcal{L}_{t_{p} \lambda}-\mathcal{L}_{t_{p} t_{p}} \mathcal{L}_{t_{r} \lambda}\right]>0 .
\end{aligned}
$$

\section{$\underline{\text { Relations with the random-auditing regime }}$}

We have shown that $t_{p}^{F A}$ and $t_{r}^{F A}$ vary in the same way as under random auditing. But, as they are constrained to move according to $d t_{r} /\left.d t_{p}\right|_{\pi_{p}^{F A=1}}$, they necessarily have to verify $t_{p}^{F A}>t_{p}^{A}$ and $t_{r}^{F A}<t_{r}^{A}$.

Moreover, as we previously proved that $\lim _{\delta \rightarrow \delta_{0}} \partial \pi_{p}^{A} / \partial \delta>0$, if $\pi_{p}=1$ within an interval $\left[\delta_{1}, \delta_{2}\right]$, it follows that $\delta_{1}>\delta_{0}$ 